Oil Prices, External Income, and Growth: Lessons from Jordan

Kamiar Mohaddes and Mehdi Raissi

8 December 2011

CWPE 1164 


\title{
Oil Prices, External Income, and Growth: Lessons from Jordan*
}

\author{
Kamiar Mohaddes ${ }^{\mathrm{a}}$ and Mehdi Raissi ${ }^{\mathrm{b} \dagger}$ \\ a Faculty of Economics and Girton College, University of Cambridge, UK \\ b International Monetary Fund, Washington DC, USA
}

December 8, 2011

\begin{abstract}
This paper extends the long-run growth model of Esfahani et al. (2009) to a labour exporting country that receives large inflows of external income - the sum of remittances, FDI and general government transfers - from major oil exporting economies. The theoretical model predicts real oil prices to be one of the main long-run drivers of real output. Using quarterly data between 1979 and 2009 on core macroeconomic variables for Jordan and a number of key foreign variables, we identify two long-run relationships: an output equation as predicted by theory and an equation linking foreign and domestic inflation rates. It is shown that real output in the long run is shaped by (i) oil prices through their impact on external income and in turn on capital accumulation, and (ii) technological transfers through foreign output. The empirical analysis of the paper confirms the hypothesis that a large share of Jordan's output volatility can be associated with fluctuations in net income received from abroad. External factors, however, cannot be relied upon to provide similar growth stimuli in the future, and therefore it will be important to diversify the sources of growth in order to achieve a high and sustained level of income.
\end{abstract}

JEL Classifications: C32, C53, E17, F43, F47, Q32.

Keywords: Growth models, long-run relations, Jordanian economy, remittances, FDI, oil price shocks, foreign output and inflation shocks, and error correcting relations.

\footnotetext{
${ }^{*}$ We are grateful to Paul Cashin, Moataz El Said, Annette Kyobe, Hashem Pesaran, and Hirut Wolde, as well as Omar Al-Zoubi, Adel Al-Sharkas, and seminar participants at the MCD Discussion Forum Series at the IMF and the research department of the Central Bank of Jordan for constructive comments and suggestions. The views expressed in this paper are those of the authors and do not necessarily represent those of the International Monetary Fund or IMF policy.

${ }^{\dagger}$ Corresponding author. Email address: mraissi@imf.org.
} 


\section{Introduction}

This paper generalizes the modeling framework of Esfahani et al. (2009) to an oil-importing but labor-exporting small open economy which receives large inflows of external income (remittances, grants, and foreign direct investment) from oil-rich countries, and examines the importance of external income shocks (mainly arising from oil price disturbances) in the growth dynamics of the country. We derive a long-run output relation under the assumption that the external income to GDP ratio of the labor-exporting country is expected to remain high over a prolonged period. The empirical validity of this relationship for the Jordanian economy is examined within a cointegrating vector autoregressive model featuring exogenous variables (VARX* model). The resultant model consists of a set of endogenous variables, including real GDP, consumer price index (CPI) inflation, real exchange rate, and the differential between the foreign interest rate and the Central Bank of Jordan rediscount (policy) rate. It also incorporates a number of key foreign variables, namely the rest of the worlds' output, inflation, and interest rate. These foreign variables are constructed as weighted averages of the corresponding variables in thirty-three major trading partners of Jordan, with the weights being the relative size of their trades with Jordan (exports plus imports).

A number of models have been estimated for the Jordanian economy in the past, such as International Monetary Fund (1998), Maziad (2009), and Beidas-Strom and Poghosyan (2011) among others, though most of these models do not have a coherent global dimension and interdependencies between the domestic and foreign variables are not explicitly modelled. Jordan as a small open economy with close trade/financial linkages with the rest of the world is expected to be strongly influenced by developments in the world economy, such as by changes in the foreign interest rates, international oil price movements, and global economic growth. Monetary policy positions taken by other countries are also likely to affect Jordan's macroeconomy, given its fixed exchange rate regime and open capital account. However, little is known or has been previously done regarding the significance of these factors in shaping Jordan's macroeconomic growth. We therefore develop a framework that features: 1) a theory derived long-run output equation that recognizes the importance of oil price movements (and so external income) for long-run growth; 2) a careful and parsimonious approach to incorporating foreign variables into the macroeconomic equations in Jordan; 3 ) joint modeling/estimation of the model variables so that we account for the simultaneity problem; 4) use of quarterly data; and 5) a bootstrap non-parametric method that addresses the problem of small sample data as the model has only 121 observations only. This method is later applied to test the number of cointegrating relations and the significance of LR statistics of the over-identifying restrictions, as well as to obtain confidence intervals for the impulse responses.

We estimate the VARX* model subject to exact and over-identifying restrictions using quarterly data over the period 1979Q2 to 2009Q4. As shown in Pesaran and Smith (2006), the VARX* model can be derived as the solution to a small open economy Dynamic Stochastic General Equilibrium (DSGE) model. Therefore, it is possible in principle to impose shortand long-run DSGE-type restrictions on the model, though in this paper we shall focus on the long-run relations and leave the short-run parameters unrestricted. We incorporate those key relations from economic theory that can be expected to have an important effect on the Jordanian economy. One of these long-run restrictions is the augmented output 
equation, which postulates a relationship between domestic output, foreign GDP, the real exchange rate, and external income. Another is the inflation differential equation, which establishes a long-run relation between domestic and foreign inflations. We make use of the generalized impulse response functions to analyze the dynamic properties of the model following a shock to exogenous variables (oil prices, foreign inflation, and the output of Jordan's trading partners). We also examine, through persistence profiles, the speed of adjustment to the long-run relations following a system-wide shock.

The empirical results indicate that the augmented output equation and the relation involving the co-movements of domestic and foreign inflations are not rejected within the model. The latter supports the purchasing power parity (PPP) relationship while the former shows that external income (here defined as the sum of remittances, grants, and FDI) contributes to real output in the long run through the accumulation of capital. Once the effects of external income are taken into account, the estimates support output convergence between Jordan and the rest of the world. Furthermore, it is not possible to reject the hypothesis that there are no linear trends in the cointegrating relations. We also show that these two long-run relations have well-behaved persistence profiles in which the effects of system-wide shocks are transitory and die out eventually. Finally, we provide evidence for the importance of oil price shocks for the Jordanian economy in our impulse response analysis.

The rest of the paper is organized as follows. Section 2 presents the theory-based long-run restrictions that can be tested within the Jordanian VARX* model. Section 3 introduces the data, and discusses the main macroeconomic trends in Jordan during the period 1979-2009. Section 4 sets out the vector error correction (VECX*) model that nests the long-run restrictions. The theory-driven long-run relationships are tested within the model and imposed when acceptable in Section 5. The short-run dynamics are discussed in Section 6 where we provide evidence on the speed of convergence to equilibrium, impulse responses, and error correction estimates. Finally, Section 7 concludes and offers some policy recommendations.

\section{The Theoretical Model}

This section modifies the long-run output equation derived in Esfahani et al. (2009) - for oil-exporting countries such as Iran, Norway and Saudi Arabia - to also apply to countries that export labour to oil-abundant economies and in turn receive large inflows of remittances, FDI and/or grants. We argue that oil price booms have two opposite effects on the GDP of the latter economies. The direct negative effect is through the increase in the import bill due to higher oil prices, while the indirect positive effect is as a result of larger inflows of external income. The latter effect might dominate the former if the ratio of external income to GDP remains relatively stable (or increases) over time. Therefore, oil prices might be one of the main long-run drivers of real output for countries such as Jordan which experiences large inflows of external income. Empirical evidence for this idea is provided in Section V.

\subsection{Long Run Output Equation}

Figure 1 shows the share of external income in GDP together with the ratio of remittances to income for the Jordanian economy. We refer to external income, $X_{t}$, as the sum of general 
government transfers, workers' remittances, and foreign direct investment (FDI). As can be seen from this figure, both remittances and external income account for a significant share of Jordan's output. Given that the majority of Jordanian migrant workers reside in the neighboring Gulf Cooperation Council (GCC) countries and that most of the official government transfers (grants) are received either from Saudi Arabia or the United States, any economic/political developments in the oil-exporting states of the region would significantly affect the flow of external income to Jordan.

\section{Figure 1: External Income and Remittances to GDP Ratios}

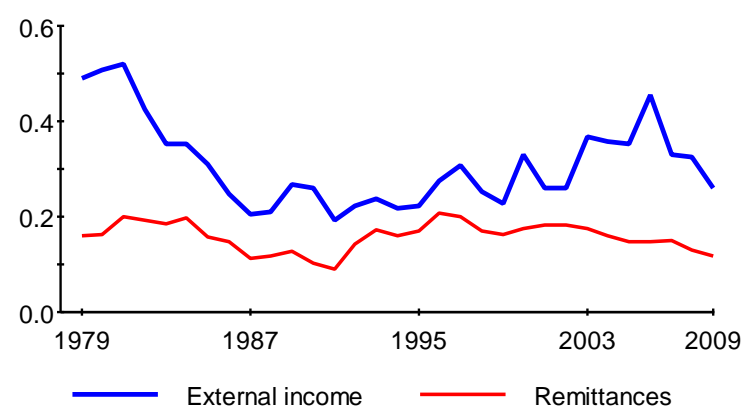

Source: Authors' construction based on data from International Monetary Fund (2010a).

Higher oil prices, ${ }^{1} P_{t}^{\text {oil }}$, in particular have a direct negative impact and an indirect positive effect on the Jordanian economy. While an increase in oil prices initially implies higher import costs for Jordan, it also reflects the boom in oil-exporting economies and as such higher external income flows into Jordan. Therefore, even though the country is an oil importer, as long as $X_{t}$ from the oil-exporting economies are maintained, we expect higher oil prices to have a long-run positive growth effect on the Jordanian economy. That is, the direct negative effect of oil price booms is dominated by the indirect positive impact; see also International Monetary Fund (2010c).

Figure 2 shows the relationship between log external income, $x_{t}$, and log oil prices, $p_{t}^{\text {oil }}$. It is clear that both variables share the same trend over the long run, with some important short-run deviations. Estimating a cointegrating $\operatorname{VAR}(2)$ model for external income and oil prices, the cointegration rank test statistics in Table 1 suggest that there is a long-run relation between $x_{t}$ and $p_{t}^{\text {oil }}{ }^{2}$. It is also interesting that the co-trending restriction, which imposes a coefficient of zero on the trend component of the long-run relationship between the two variables, is not rejected and the hypothesis that the long-run elasticity of external income to oil prices is unity cannot be rejected either, and as a result: $x_{t}=p_{t}^{\text {oil }}+\xi_{x, t}$, where $\xi_{x, t} \sim I(0)$. Therefore, oil prices represent an excellent proxy for external income in the Jordanian economy.

\footnotetext{
${ }^{1}$ All variables are in nominal terms unless specified otherwise.

${ }^{2}$ All estimations and test results in this paper are obtained using Microfit 5.0. For further technical details see Pesaran and Pesaran (2009), Section 22.10.
} 


\section{Figure 2: External Income and Price of Oil, in Log Level}

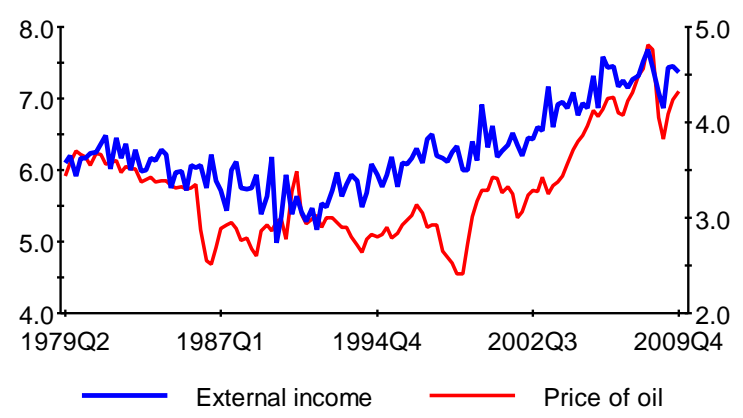

Sources: Authors' construction based on data from International Monetary Fund (2010a) and International Monetary Fund (2010e).

Table 1: Cointegration Rank Test Statistics for the VAR(2) Model with External Income and Price of Oil

\begin{tabular}{|c|c|c|c|c|}
\hline$H_{0}$ & $H_{1}$ & Test statistic & 95\% Critical Values & 90\% Critical Values \\
\hline \multicolumn{5}{|c|}{ (a) Maximal eigenvalue statistic } \\
\hline$r=0$ & $r=1$ & 20.27 & 19.22 & 17.18 \\
\hline$r \leq 1$ & $r=2$ & 5.89 & 12.39 & 10.55 \\
\hline \multicolumn{5}{|c|}{ (b) Trace statistic } \\
\hline$r=0$ & $r=1$ & 26.16 & 25.77 & 23.08 \\
\hline$r \leq 1$ & $r=2$ & 5.89 & 12.39 & 10.55 \\
\hline
\end{tabular}

Notes: The test statistics refer to Johansen's log-likelihood-based maximum eigenvalue and trace statistics and are computed using 121 observations from 1979Q4 to 2009Q4.

The persistence of the external income flows to Jordan from the GCC countries and other oil exporters partly depends on the ability of the latter group to keep producing oil in the long run, as well as on the stability of oil revenues to GDP ratios in these economies over a prolonged period. For major oil exporting countries, of which many started oil extraction and exports in the beginning of the 20th century, the reserve-to-extraction ratio indicates that they are capable of producing for many more decades even in the absence of new oil field discoveries or major advances in oil exploration and extraction technologies.

However, while it is clear that the oil and gas reserves will be exhausted eventually, this is likely to take place over a relatively long period. Figure 3 shows that most OPEC (Organization of the Petroleum Exporting Countries) members such as Algeria, Iran, Kuwait, Nigeria, Saudi Arabia, United Arab Emirates, and Venezuela, and a few countries outside OPEC such as Norway and Russia, have similar oil income to GDP ratios that have remained relatively stable (and in some cases have even been rising as in Norway). Therefore, there is little evidence to suggest that oil income will be diminishing any time soon in these 
Figure 3: Oil Export Revenues to Income Ratios for Major Oil Exporters

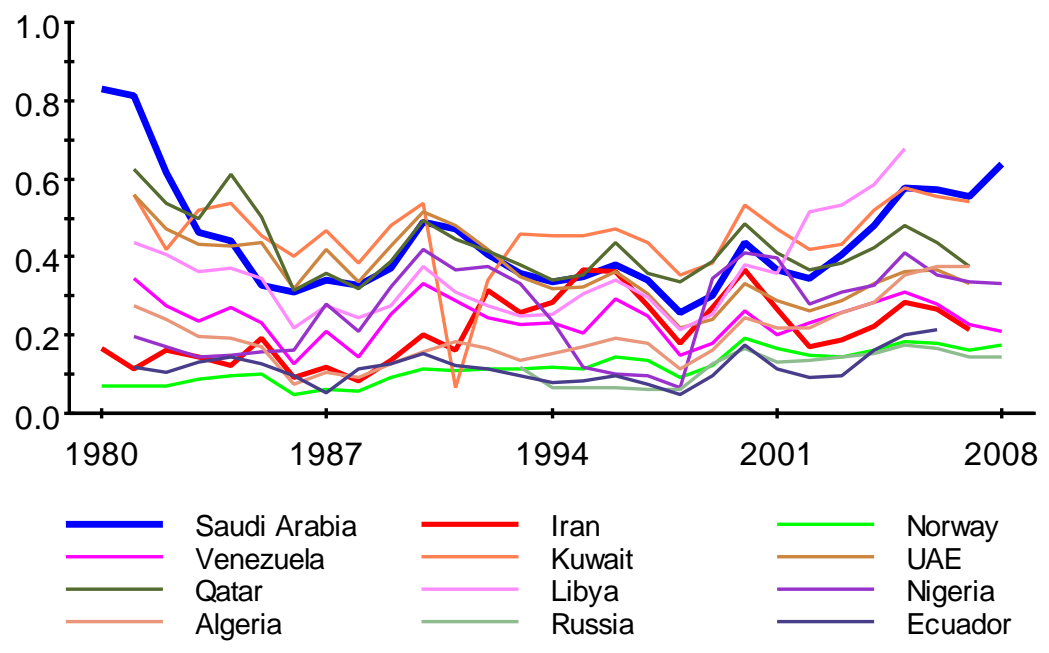

Source: Authors' construction based on data from British Petroleum (2010), OPEC (2009), and International Monetary Fund (2010e).

economies. ${ }^{3}$ As a result, external income flows to Jordan are not likely to go away any time soon either, and so the effects of $x_{t}$ on long-run output and economic growth will continue to be substantial and should be explicitly modelled.

To this end, we augment the output gap equation derived in Esfahani et al. (2009), to include oil prices as opposed to oil export revenues. The justification for our modelling strategy of using oil prices rather than external income as one of the main long-run drivers of real output for Jordan is given in the discussion above, where we established that the price of oil is an excellent proxy for external income. The above results also showed that from a long run perspective, only one of the two variables $\left(x_{t}\right.$ or $\left.p_{t}^{\text {oil }}\right)$ need to be included in the cointegrating model. Our decision to include oil prices rather than external income is further justified on the ground that $p_{t}^{\text {oil }}$ is likely to be exogenous to the Jordanian economy whilst the same cannot be said of $x_{t}$. Furthermore, the inclusion of $p_{t}^{\text {oil }}$ will give us the net effect of higher oil prices on the equilibrium output level, while the inclusion of $x_{t}$ will only show the positive indirect impact of higher oil prices on GDP and not the direct negative effects. For now, we make use of the price of oil, but in Section 5.3.2 we will investigate how the equilibrium relationship changes if external income is included in the model instead.

The modified output gap equation for Jordan is then given by:

$$
y_{t}-\psi_{1} y_{t}^{*}=\psi_{2}\left(e_{t}-p_{t}\right)+\psi_{3} p_{t}^{o i l}+c_{y}+\gamma_{y} t+\xi_{y, t},
$$

where $y_{t}\left(y_{t}^{*}\right)$ is the logarithm of real domestic (foreign) output, $e_{t}$ is the log of the nominal exchange rate, $p_{t}$ is the logarithm of the domestic Consumer Price Index (CPI), $p_{t}^{\text {oil }}$ is the

\footnotetext{
${ }^{3}$ See Esfahani et al. (2009) for an extensive discussion.
} 
$\log$ of nominal oil prices, $c_{y}$ is a fixed constant, and $\xi_{y, t}$ is a mean zero stationary process, which represents the error correction term of the long-run output equation. As discussed in Section 2.1 in Esfahani et al. (2009), the coefficient of the variables in equation (1) have further restrictions imposed on them based on economic theory, namely:

$$
\psi_{1}=\theta\left(1-\psi_{2}\right), \psi_{2}=\psi_{3}=\alpha, \text { and } \gamma_{y}=(1-\alpha)\left(n-\theta n^{*}\right),
$$

where $\alpha$ is the share of capital in output, $n\left(n^{*}\right)$ is the domestic (foreign) population growth rate, and $\theta$ measures the extent to which foreign technology is diffused and adapted successfully by the domestic economy in the long run. The diffusion of technology is at par with the rest of the world if $\theta=1$, whilst a value of $\theta$ below unity suggests inefficiency that prevents the adoption of best practice techniques, possibly due to rent-seeking activities. When $\theta>1$, steady state per capita output growth in Jordan can only exceed that of its trading partners if external income per capita is rising faster than the steady state per capita output in the rest of the world. However, if $\theta<1$, the steady state output growth in Jordan would be lower than the rest of the world's per capita output growth.

\subsection{Other Long Run Relations}

In addition to the output equation, we also consider the relationship between domestic $\left(\pi_{t}=p_{t}-p_{t-1}\right)$ and foreign $\left(\pi_{t}^{*}=p_{t}^{*}-p_{t-1}^{*}\right)$ inflation rates:

$$
\pi_{t}-\phi_{1} \pi_{t}^{*}=c_{\pi}+\gamma_{\pi} t+\xi_{\pi, t},
$$

where $c_{\pi}$ is a fixed constant and $\xi_{\pi, t}$ is the stationary error correcting term for the relationship between domestic and foreign inflation. This is in fact one of the long-run relationships in a canonical New Keynesian Model; see Pesaran and Smith (2006) for more details. In addition, equation (3) can also be derived from the Purchasing Power Parity (PPP) equation. To see this, note that if PPP holds we have:

$$
p_{t}-p_{t}^{*}-e_{t}=c_{p}+\gamma_{p} t+\xi_{p, t},
$$

where $c_{p}$ is a fixed constant and $\xi_{p, t}$ is the stationary error correcting term for the PPP relationship, but given a fixed exchange rate regime (which Jordan has maintained for several years), taking the difference of equation (4) yields (3).

A number of other long-run relations are also considered in the literature, namely the money demand function, the uncovered interest parity condition and the Fisher equation; see Garratt et al. (2006) for further details. However, considering that Jordan has maintained a peg with the U.S. dollar since 1995 as well as an open capital account, the domestic interest rate and the real money balance, as instruments for monetary policy, are exogenously determined and therefore we do not consider those long-run relationships here.

Our modelling strategy closely follows Esfahani et al. (2009) and Garratt et al. (2003) in estimating a cointegrating VARX* model with $\mathbf{x}_{t}=\left(y_{t}, \pi_{t}, e_{t}-p_{t}, r_{t}-r_{t}^{*}\right)^{\prime}$ as the endogenous variables, and $\mathbf{x}_{t}^{*}=\left(y_{t}^{*}, \pi_{t}^{*} p_{t}^{\text {oil }}\right)^{\prime}$ as the exogenous variables. It is also possible to extend the model to include other macro variables such as consumption and investment, but given the long run focus of our analysis, the inclusion of these variables are unlikely to alter the cointegrating relationship that we estimate between real output and external income. Before giving the details of the econometric model in Section IV, we first discuss the data and the main economic trends of the Jordanian economy over the period 1979Q1-2009Q4. 


\subsection{Application to Other Countries}

The modified output gap equation suggested in this paper for Jordan is also applicable to other countries that export labour to major oil-abundant economies and in return receive large grants and/or remittances. That is, as long as the ratio of external income to GDP is expected to be relatively stable or increasing over time, oil price changes are expected to have a long-run effect on output growth of these economies.

The external income to GDP ratio of nine labour-exporting countries, with large inflows of remittances from oil producing economies, is shown in Figure 4. It is clear that this ratio has substantially increased over time for almost all of these countries. Therefore, the theory-derived output gap equation (1) could also be tested using macro data from these countries. We will concentrate on Jordan in the remainder of this paper, but a future paper will investigate the role of oil in these other remittance-dependant economies.

\section{Figure 4: External Income to GDP Ratios}

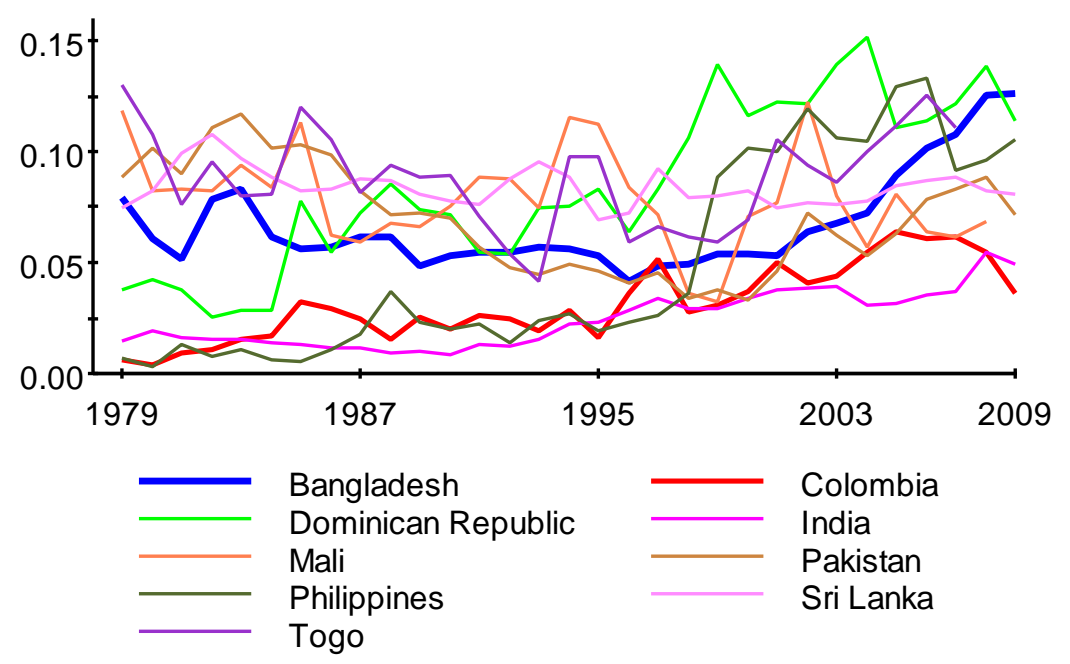

Sources: Authors' construction based on data from International Monetary Fund (2010a) and International Monetary Fund (2010e).

\section{Data}

\subsection{Construction of Macro Variables}

Our dataset contains quarterly observations on Jordan and another 33 countries, from the first quarter of 1979 to the fourth quarter of 2009. The domestic variables included are $\log$ real output, $y_{t}, \log$ short-term interest rates, $r_{t}, \log$ price level, $p_{t}$, the rate of inflation, 
$\pi_{t}=p_{t}-p_{t-1}, \log$ nominal exchange rate, $e_{t}$, and log external income, $x_{t}$. Specifically,

$$
\begin{aligned}
& y_{t}=\ln \left(G D P_{t}\right), \quad r_{t}=0.25 \ln \left(1+R_{t} / 100\right), \\
& e_{t}=\ln \left(E_{t}\right), \quad p_{t}=\ln \left(C P I_{t}\right), \quad x_{t}=\ln \left(X_{t}\right),
\end{aligned}
$$

where $G D P_{t}$ is the real Gross Domestic Product, $R_{t}$ is the short-term interest rate, $E_{t}$ is the number of domestic currency (dinars) per one US dollar exchanged on free markets, $C P I_{t}$ is the consumer price index, and $X_{t}$ is the external income calculated as the sum of general government transfers, workers' remittances, and foreign direct investment (FDI).

Quarterly data on GDP is available from International Monetary Fund (2010e) since 1992Q1, while annual data is available from 1959. We seasonally adjust the quarterly observations using the U.S. Census Bureau's X-12 ARIMA seasonal adjustment program. ${ }^{4}$ Quarterly series between 1979Q1 and 1991Q4 are then interpolated (backwards) linearly from the annual series using the same method as that applied by Dees et al. (2007). We obtain quarterly observations on the nominal exchange rate and CPI from International Monetary Fund (2010d) and the end of period discount rate from International Monetary Fund (2010e). CPI data is then seasonally adjusted using X-12 ARIMA. Finally, external income is constructed using data from International Monetary Fund (2010a).

The four exogenous variables in the model are foreign output, $y_{t}^{*}$, foreign price level, $p_{t}^{*}$, foreign short-term interest rates, $r_{t}^{*}$, and oil prices, $p_{t}^{\text {oil }}=\ln \left(P_{t}^{\text {oil }}\right)$, where $P_{t}^{\text {oil }}$ is the nominal price of oil per barrel in US dollars. The foreign variables were computed as the trade weighted averages of the corresponding domestic variables $\left(y_{j t}, r_{j t}, p_{j t}\right)$ of Jordan's trading partners:

$$
y_{t}^{*}=\sum_{j=1}^{N} \omega_{j} y_{j t}, \quad r_{t}^{*}=\sum_{j=1}^{N} \omega_{j} r_{j t}, \quad p_{t}^{*}=\sum_{j=1}^{N} \omega_{j} p_{j t}
$$

where $N=33, j=1,2 \ldots, N$, and

$$
\omega_{j}=\frac{T_{j, 2006}+T_{j, 2007}+T_{j, 2008}}{T_{2006}+T_{2007}+T_{2008}},
$$

where $T_{j t}$ is the bilateral trade of Jordan with country $j$ during a given year $t$ and is calculated as the average of exports and imports of Jordan with that country, and $T_{t}=\sum_{j=1}^{N} T_{j t}$, for $t=2006,2007,2008$. The trade weights are computed based on data from International Monetary Fund (2010b) and data on the foreign variables are obtained from Smith and Galesi (2010). The 33 countries included in these weighted averages are: Argentina, Australia, Austria, Belgium, Brazil, Canada, China, Chile, Finland, France, Germany, India, Indonesia, Italy, Japan, Korea, Malaysia, Mexico, Netherlands, Norway, New Zealand, Peru, Philippines, South Africa, Saudi Arabia, Singapore, Spain, Sweden, Switzerland, Thailand, Turkey, United Kingdom, and United States. These countries were chosen as we wish to later link the Jordanian model specified here to the Global VAR (GVAR) framework initially developed in Pesaran (2004).

\footnotetext{
${ }^{4}$ For further information see U.S. Census Bureau (2007): X-12-ARIMA Reference Manual at http://www.census.gov/srd/www/x12a/
} 
Based on these weights, the most important trading partner of Jordan is Saudi Arabia, which accounts for 26 percent of its total trade. A further 19 percent of Jordanian trade originates in or is destined to the eight euro area economies in our dataset, with Germany (7 percent) being Jordan's most important trading partner in Europe. Other important trade partners are the United States, China, and India, accounting for 14, 11, and 8 percent of total Jordanian trade, respectively.

\subsection{Macroeconomic Trends in Jordan 1979-2009}

In recent decades, Jordan has undergone a transformation from an inward-oriented, mostly state-controlled economy, to an export-oriented country led by a dynamic private sector. The macroeconomic situation in Jordan is closely tied to those of other countries in the Middle East. Remittances from Jordanians working in other countries, especially in the Persian Gulf states, are an important source of national income (equivalent to 15-20 percent of GDP, see Figure 1); the Persian Gulf region is the primary destination for Jordanian exports, and in turn, supplies most of its energy requirements; and the country receives substantial grants and foreign direct investments (FDI) from other states in the region.

These inflows of external income (remittances, grants and FDI) explain the shifting trends apparent in Jordan's recent economic history (see Figure 5). During the first half of the 1980s, Jordan experienced favorable macroeconomic conditions aided by foreign grants and the regional economic boom associated with high oil prices. The public sector expanded with government investment being financed to a large extent by grants and loans from oilexporting countries in the region. Private investment and income levels also increased due to higher workers' remittances. However, given the incentive structure and price signals, much of the private investment was directed to housing construction and mineral-based processing sectors, while export-oriented manufacturing activities were slow to develop.

During the second half of the 1980s, as the flow of external income started to decline in the aftermath of the oil price collapse, Jordan's underlying imbalances came to the fore. The country responded to these developments initially by resorting to external and domestic commercial bank borrowing to finance unsustainable levels of aggregate demand and increasingly large budget deficits. As a result of an easing of the credit stance and a large devaluation, inflation started picking up and reached its highest values by the end of the 1980s (Figure 5f). Moreover, with the slowdown in economic activity in Jordan (and high interest rates in world markets), the debt burden reached unsustainable proportions, and Jordan's vulnerability was exacerbated. By that time, the external debt exceeded annual GDP by nearly twofold, official foreign exchange reserves had declined below one month of imports, and a major balance of payments crisis occurred in 1988-89; see International Monetary Fund (1998) for more details.

To address the rapidly-growing imbalances, Jordan adopted an adjustment program with the IMF in 1989, which resulted in some progress in the reduction of macroeconomic imbalances and the introduction of structural reforms. These adjustment and reform efforts were interrupted (temporarily) by the Gulf War and the return of Jordanian workers expelled from Kuwait in 1991-92, leading to a sharp decline in foreign aid, and remittances. Post crisis, the economic performance has been marked by successful disinflation and fluctuations in real GDP over a wide range (Figures 5a and 5f). GDP rebounded strongly in 1992 on 
account of an investment boom funded by the savings that "returnees" brought back to Jordan. However, the spike was short-lived and GDP growth has remained more stable since the mid-1990s.

After the crisis of 1989, the first priority of macroeconomic policies was to restore stability and confidence in the Jordanian dinar (which was devalued by almost 50 percent against the U.S. dollar; see Figure 5d). Confidence in the dinar was restored only after a number of years and following a series of exchange rate arrangements. The initial stabilization, based on a peg of the Jordanian dinar to a basket of currencies comprising the Special Drawing Rights (SDR), was effective in moderating inflation. Between May 1989 and October 1995, the peg was adjusted frequently with a view to ensuring competitiveness, while the Jordanian dinar was fully stabilized after the switch of the peg to the U.S. dollar alone in November 1995. The peg provided a transparent framework for monetary policy that brought about the gradual strengthening of international reserves and the co-movement of domestic and foreign inflation rates (as shown in Figure 5f). Inflation declined to advanced country levels and price stability was fully achieved by 1999. Given the exchange rate peg adopted by the Central Bank of Jordan (CBJ) as the monetary policy framework, the differential between the foreign interest rate and CBJ rediscount (policy) rate can be viewed as a good proxy for the stance of monetary policy.

Jordan's economy today is very different from that of the early 1990s. Prudent macroeconomic policies and effective structural reforms, namely: (i) liberalizing foreign trade, capital account, and domestic prices; (ii) reducing public debt; and (iii) privatizing state-owned enterprises, have transformed Jordan into one of the most open and dynamic export-led economies in the region. However, the country's close regional economic ties through external income shall make it susceptible to shocks related to economic and political developments in the Persian Gulf and the wider Middle East, including oil price shocks.

\section{A VARX* Error Correction Model for Jordan}

We begin our analysis by showing how the two long-run relations given by equations (1) and (3) can be embodied in a vector error correction model. We first note that the two long-run relations can be written compactly as deviations from equilibrium:

$$
\boldsymbol{\xi}_{t}=\boldsymbol{\beta}^{\prime} \mathbf{z}_{t}-\mathbf{c}-\gamma t
$$

where

$$
\begin{aligned}
\mathbf{z}_{t} & =\left(\mathbf{x}_{t}^{\prime}, \mathbf{x}_{t}^{* \prime}\right)^{\prime}=\left(y_{t}, \pi_{t}, e_{t}-p_{t}, r_{t}-r_{t}^{*}, y_{t}^{*}, \pi_{t}^{*}, p_{t}^{o i l}\right)^{\prime} \\
\mathbf{c} & =\left(c_{y}, c_{\pi}\right)^{\prime}, \boldsymbol{\gamma}=\left(\gamma_{y}, \gamma_{\pi}\right)^{\prime}, \boldsymbol{\xi}_{t}=\left(\xi_{y, t}, \xi_{\pi, t}\right)^{\prime}
\end{aligned}
$$

and

$$
\boldsymbol{\beta}^{\prime}=\left(\begin{array}{ccccccc}
-1 & 0 & \psi_{2} & 0 & \psi_{1} & 0 & \psi_{3} \\
0 & -1 & 0 & 0 & 0 & \phi_{1} & 0
\end{array}\right)
$$

The long-run theory for oil exporting countries, as derived in Section 2.1 in Esfahani et al. (2009), requires two further restrictions on the output equation (1) for Jordan, namely $\psi_{2}=\psi_{3}=\alpha$ and $\psi_{1}=\theta(1-\alpha)$, where we are interested in seeing whether in fact the 


\section{Figure 5: Macroeconomic Variables for Jordan, in Log Level}

(a) Domestic and foreign output

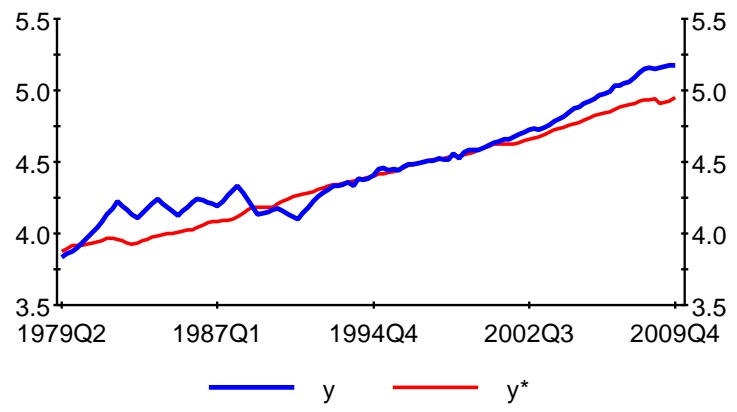

(c) External income

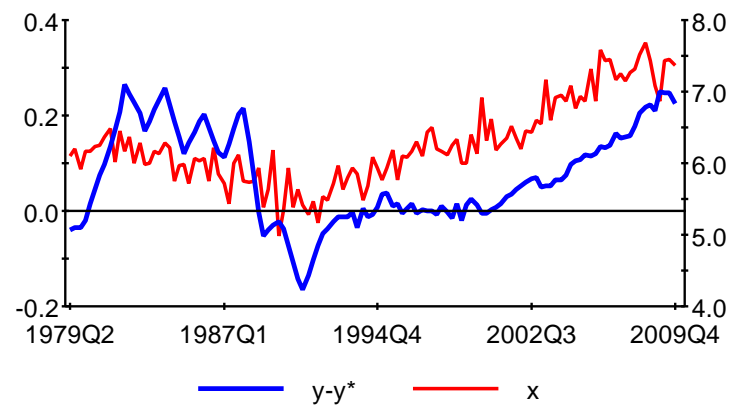

(e) The spread between domestic and foreign interest rates

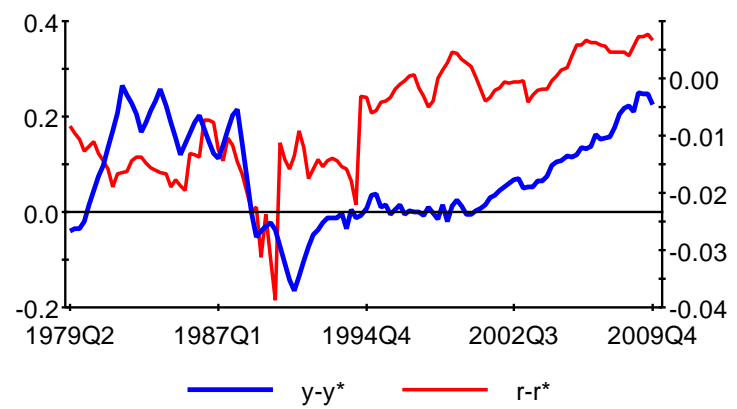

(b) Price of oil

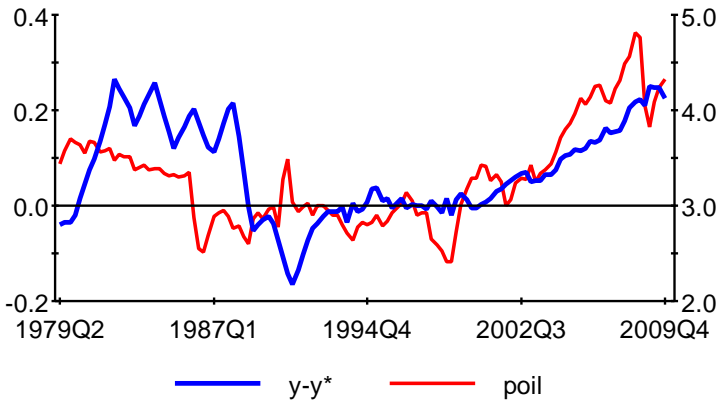

(d) Real exhange rate

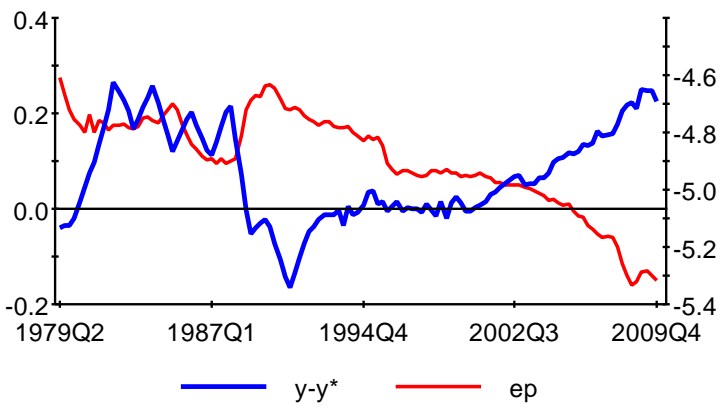

(f) Domestic and foreign inflation

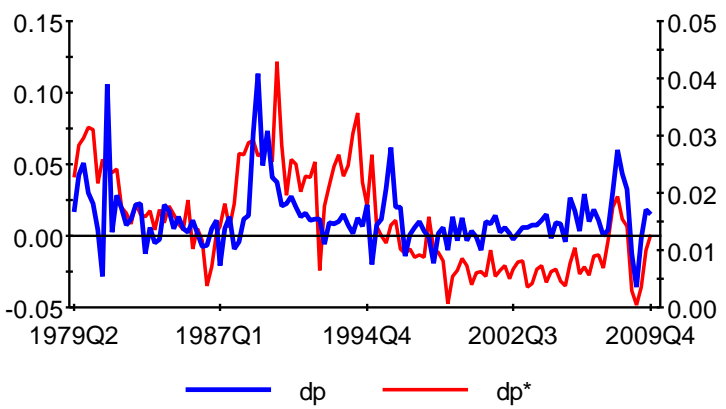

Notes: The second variable in each of the figures (a) to (f) should be read using the right-hand scale. Authors' construction based on data from International Monetary Fund (2010a), International Monetary Fund (2010b), International Monetary Fund (2010d), and International Monetary Fund (2010e). 
coefficients on the real exchange rate and nominal oil prices are the same and equal to the share of capital in output $(\alpha)$, and whether technological progress in Jordan is on par with that of the rest of the world; in other words, whether $\theta=1$, and as a result the coefficient on foreign real output is equal to $(1-\alpha)$.

The $\operatorname{VARX}^{*}\left(s, s^{*}\right)$ model that embodies $\boldsymbol{\xi}_{t}$ is constructed from a suitably restricted version of the VAR in $\mathbf{z}_{t}$. In the present application, $\mathbf{z}_{t}=\left(\mathbf{x}_{t}^{\prime}, \mathbf{x}_{t}^{* \prime}\right)^{\prime}$ is partitioned into a $4 \times 1$ vector of endogenous variables, $\mathbf{x}_{t}=\left(y_{t}, \pi_{t}, e_{t}-p_{t}, r_{t}-r_{t}^{*}\right)$, and a $3 \times 1$ vector of the weakly exogenous variables, $\mathbf{x}_{t}^{*}=\left(y_{t}^{*}, \pi_{t}^{*}, p_{t}^{o i l}\right)^{\prime}$. Also as shown in Section V.A, the hypothesis that all the seven variables are $I(1)$ cannot be rejected. Moreover, it is easily established that the three exogenous variables are not cointegrated. Under these conditions, following Pesaran et al. (2000), the VAR in $\mathbf{z}_{t}$ can be decomposed into the conditional model for the endogenous variables:

$$
\Delta \mathbf{x}_{t}=-\boldsymbol{\Pi}_{x} \mathbf{z}_{t-1}+\sum_{i=1}^{s-1} \boldsymbol{\Psi}_{i} \Delta \mathbf{x}_{t-i}+\boldsymbol{\Lambda}_{0} \Delta \mathbf{x}_{t}^{*}+\sum_{i=1}^{s^{*}-1} \boldsymbol{\Lambda}_{i} \Delta \mathbf{x}_{t-i}^{*}+\mathbf{a}_{0}+\mathbf{a}_{1} t+\boldsymbol{v}_{t},
$$

and the marginal model for the exogenous variables:

$$
\Delta \mathbf{x}_{t}^{*}=\sum_{i=1}^{s-1} \Gamma_{i}^{*} \Delta \mathbf{z}_{t-i}+\mathbf{b}_{0}+\mathbf{u}_{x^{*} t}
$$

If the model includes an unrestricted linear trend, in general there will be quadratic trends in the level of the variables when the model contains unit roots. To avoid this, the trend coefficients are restricted such that $\mathbf{a}_{1}=\boldsymbol{\Pi}_{x} \boldsymbol{\delta}$, where $\boldsymbol{\delta}$ is an $7 \times 1$ vector of free coefficients; see Pesaran et al. (2000) and Section 6.3 in Garratt et al. (2006). The nature of the restrictions on $\mathbf{a}_{1}$ depends on the rank of $\boldsymbol{\Pi}_{x}$. In the case where $\boldsymbol{\Pi}_{x}$ is full rank, $\mathbf{a}_{1}$ is unrestricted, whilst it is restricted to be equal to $\mathbf{0}$ when the rank of $\boldsymbol{\Pi}_{x}$ is zero. Under the restricted trend coefficients, the conditional model can be written as:

$$
\Delta \mathbf{x}_{t}=-\boldsymbol{\Pi}_{x}\left[\mathbf{z}_{t-1}-\boldsymbol{\delta}(t-1)\right]+\sum_{i=1}^{s-1} \boldsymbol{\Psi}_{i} \Delta \mathbf{x}_{t-i}+\boldsymbol{\Lambda}_{0} \Delta \mathbf{x}_{t}^{*}+\sum_{i=1}^{s^{*}-1} \Lambda_{i} \Delta \mathbf{x}_{t-i}^{*}+\tilde{\mathbf{a}}_{0}+\boldsymbol{v}_{t}
$$

where $\tilde{\mathbf{a}}_{0}=\mathbf{a}_{0}+\boldsymbol{\Pi}_{x} \boldsymbol{\delta}$. We refer to this specification as the vector error correction model with weakly exogenous $I(1)$ variables, or $\operatorname{VECX}^{*}\left(s, s^{*}\right)$ for short. Note that $\tilde{\mathbf{a}}_{0}$ remains unrestricted since $\mathbf{a}_{0}$ is not restricted. While for consistent and efficient estimation (and inference), we only require the conditional model as specified in equation (9), for impulse response analysis and forecasting, we need the full system vector error correction model which also includes the marginal model; as such, we need to specify the process driving the weakly exogenous variables, $\Delta \mathbf{x}_{t}^{*}$.

Long-run theory imposes a number of restrictions on $\boldsymbol{\Pi}_{x}$ and $\boldsymbol{\delta}$. First, for the conditional model to embody the equilibrium errors defined by equation (7), we must have $\boldsymbol{\Pi}_{x}=\boldsymbol{\alpha}_{x} \boldsymbol{\beta}^{\prime}$, which in turn implies that $\operatorname{rank}\left(\boldsymbol{\Pi}_{x}\right)=2$. Furthermore, the restrictions on the trend coefficients are given by

$$
\Pi_{x} \boldsymbol{\delta}=\boldsymbol{\alpha}_{\mathbf{x}} \boldsymbol{\beta}^{\prime} \boldsymbol{\delta}=\boldsymbol{\gamma} .
$$

Since under cointegration $\boldsymbol{\alpha}_{x} \neq \mathbf{0}$, it then follows that a trend will be absent from the longrun relations if one of the two elements of $\boldsymbol{\beta}^{\prime} \boldsymbol{\delta}$ is equal to zero. These restrictions are known 
as co-trending restrictions, meaning that the linear trends in the various variables of the long-run relations get cancelled out. This hypothesis is important in the analysis of output convergence between domestic and the foreign variables, since without such a co-trending restriction the two output series will diverge even if they are shown to be co-integrated.

The theory also imposes a number of long-run over-identifying restrictions on the elements of $\boldsymbol{\beta}$. The total number of over-identifying restrictions is given by $14-4=10$, and there are 3 structural parameters to be estimated, $\alpha, \theta$, and $\phi_{1}$. This leaves us with 7 over-identifying restrictions to test.

\section{$5 \quad$ Long-Run Estimates and Tests}

\subsection{Unit Root Test Results}

Before estimating equation (11), and to make sure that we make sensible interpretations of the long-run relations, we need to consider the unit root properties of the core variables in our model $\left(y_{t}, \pi_{t}, e_{t}-p_{t}, r_{t}-r_{t}^{*}, y_{t}^{*}, \pi_{t}^{*}, p_{t}^{\text {oil }}\right)$. Table 2 reports the results of the standard Augmented Dickey-Fuller (ADF) test as well as the generalized least squares version of the Dickey-Fuller test (ADF-GLS) proposed by Elliott et al. (1996), and the weighted symmetric ADF test (ADF-WS) of Park and Fuller (1995). We report the latter tests as they both have been shown to have better power properties than the ADF test.

Table 2: Unit Root Test Statistics (based on AIC Order Selection)

(a) Unit root test statistics for the levels

\begin{tabular}{lccccccccc}
\hline & $y_{t}$ & $p_{t}$ & $e_{t}-p_{t}$ & $r_{t}-r_{t}^{*}$ & $y_{t}^{*}$ & $p_{t}^{*}$ & $p_{t}^{\text {oil }}$ & $C V$ & $C V T$ \\
\hline ADF & -0.63 & -1.93 & -2.01 & -3.32 & -2.47 & -0.80 & -1.53 & -2.89 & -3.45 \\
ADF-GLS & -0.95 & -1.60 & -2.33 & -2.21 & -1.10 & -1.05 & -1.15 & -2.14 & -3.03 \\
ADF-WS & -1.13 & -1.80 & -2.34 & -2.81 & -1.24 & -0.98 & -1.28 & -2.55 & -3.24 \\
\hline
\end{tabular}

(b) Unit root test statistics for the first differences

\begin{tabular}{lccccccccc}
\hline & $\Delta y_{t}$ & $\Delta p_{t}$ & $\Delta\left(e_{t}-p_{t}\right)$ & $\Delta\left(r_{t}-r_{t}^{*}\right)$ & $\Delta y_{t}^{*}$ & $\Delta p_{t}^{*}$ & $\Delta p_{t}^{\text {oil }}$ & $C V$ & $C V T$ \\
\hline ADF & -4.91 & -2.77 & -4.07 & -6.51 & -4.82 & -2.24 & -6.25 & -2.89 & -3.45 \\
ADF-GLS & -4.22 & -2.77 & -1.05 & -5.48 & -2.75 & -1.10 & -3.26 & -2.14 & -3.03 \\
ADF-WS & -4.91 & -2.56 & -3.36 & -6.70 & -5.01 & -1.90 & -6.49 & -2.55 & -3.24 \\
\hline
\end{tabular}

(c) Unit root test statistics for the second differences

\begin{tabular}{lccccccccc}
\hline & $\Delta^{2} y_{t}$ & $\Delta^{2} p_{t}$ & $\Delta^{2}\left(e_{t}-p_{t}\right)$ & $\Delta^{2}\left(r_{t}-r_{t}^{*}\right)$ & $\Delta^{2} y_{t}^{*}$ & $\Delta^{2} p_{t}^{*}$ & $\Delta^{2} p_{t}^{\text {oil }}$ & $C V$ & $C V T$ \\
\hline ADF & -10.51 & -8.50 & -11.10 & -9.94 & -9.35 & -10.54 & -8.58 & -2.89 & -3.45 \\
ADF-GLS & -10.56 & -8.50 & -9.96 & -9.99 & -3.69 & -9.36 & -7.52 & -2.14 & -3.03 \\
ADF-WS & -10.84 & -8.74 & -9.92 & -10.25 & -9.66 & -10.87 & -8.86 & -2.55 & -3.24 \\
\hline
\end{tabular}

Notes: ADF denotes the Augmented Dickey-Fuller Test, ADF-GLS the generalized least squares version of the ADF test, and ADF-WS the weighted least squares ADF test. The sample period runs from 1979Q2 to 2009Q4. $C V T$ gives the 95 percent simulated critical values for the test with intercept and trend, while $C V$ is the 95 percent simulated critical value for the test including an intercept only.

It is clear from Figures 5a to $5 \mathrm{f}$ that all core variables are trending, and therefore we will include a trend and an intercept in the ADF regressions for all the variables, while 
we will only include an intercept in the ADF regressions applied to their first and second differences. As can be seen from Table 2, all three tests clearly reject the unit root hypothesis when applied to the first differences of all seven variables, while this is not the case for the unit root test applied to the levels. Thus, we can safely regard $y_{t}, \pi_{t}, e_{t}-p_{t}, r_{t}-r_{t}^{*}, y_{t}^{*}, \pi_{t}^{*}$, and $p_{t}^{\text {oil }}$ as being $I(1)$.

\subsection{Order Selection and Deterministic Components}

To test the long-run theory restrictions described in Section II, we use the $\operatorname{VECX} *\left(s, s^{*}\right)$ model defined by equation (11). We include both a constant and a linear trend as deterministic variables in our model. However, as a trend may or may not be found in the long-run relations, we also test for co-trending restrictions given by $\boldsymbol{\beta}^{\prime} \boldsymbol{\delta}=\mathbf{0}$. However, before estimating equation (11), we need to determine the lag orders $s$ and $s^{*}$ in the $\operatorname{VARX}^{*}\left(s, s^{*}\right)$ model. To do this, we use the Akaike Information Criterion (AIC) and the Schwarz Bayesian Criterion (SBC) applied to the underlying unrestricted VARX* model. Since we use quarterly data, the maximum lag length considered is 4 . The results are summarized in Table 3 , from which it is clear that both AIC and SBC select the lag orders $\hat{s}=\hat{s}^{*}=2$. Thus, we base our analysis on the $\operatorname{VARX}^{*}(2,2)$. We also experimented with a VARX*(2,1) model and found the long-run estimates to be fairly similar to those of the $\operatorname{VARX}^{*}(2,2)$. These results are not reported here but are available upon request.

\section{Table 3: Lag Order Selection Criteria}

\begin{tabular}{ccc}
\hline Lag length & AIC & SBC \\
\hline$s=s^{*}=1$ & 1398.0 & 1348.0 \\
$s=s^{*}=2$ & 1440.7 & 1368.5 \\
$s=s^{*}=3$ & 1435.6 & 1341.1 \\
$s=s^{*}=4$ & 1438.6 & 1321.9 \\
\hline
\end{tabular}

Notes: AIC refers to the Akaike Information Criterion and SBC refers to the Schwarz Bayesian Criterion.

\subsection{Estimation and Testing of the Long-Run Relations}

Having chosen the order of the VARX* to be $(2,2)$ we proceed to determine the number of cointegrating relations given by $r=\operatorname{rank}\left(\boldsymbol{\Pi}_{x}\right)$, where $\boldsymbol{\Pi}_{x}$ is defined by equation (11). Table 4 reports the cointegration tests results with the null hypothesis of no cointegration $(r=0)$, one cointegrating relation $(r=1)$, and so on. These tests are carried out using Johansen's maximum eigenvalue and trace statistics as developed in Pesaran et al. (2000) for models with weakly exogenous regressors. While the maximal eigenvalue statistic suggests the presence of one cointegrating relation, the trace statistic indicates the presence of two cointegrating relations at the 5 per cent level, which is the same as that suggested by economic theory, thus we set $r=2$.

Given that $r=2$, and to exactly identify the long-run relations, we need to impose 2 restrictions on each of the 2 cointegration relations. To this end, we let the first long-run 
Table 4: Cointegration Rank Test Statistics for the VARX*(2,2) Model

\begin{tabular}{lcccc}
\hline$H_{0}$ & $H_{1}$ & Test Statistic & $95 \%$ Critical Values & 90\% Critical Values \\
\hline \multicolumn{2}{l}{ (a) } & Maximal eigenvalue statistic & & \\
$r=0$ & $r=1$ & 54.53 & 46.00 & 42.47 \\
$r \leq 1$ & $r=2$ & 35.60 & 39.37 & 35.85 \\
$r \leq 2$ & $r=3$ & 23.55 & 30.98 & 28.42 \\
$r \leq 3$ & $r=4$ & 12.89 & 22.75 & 20.02 \\
(b) Trace & statistic & & & \\
$r=0$ & $r=1$ & 126.58 & 102.19 & 95.28 \\
$r \leq 1$ & $r=2$ & 72.04 & 71.10 & 66.53 \\
$r \leq 2$ & $r=3$ & 36.44 & 43.90 & 40.74 \\
$r \leq 3$ & $r=4$ & 12.89 & 22.75 & 20.02 \\
\hline
\end{tabular}

Notes: The underlying VARX* model is of order $(2,2)$ and contains unrestricted intercept and restricted trend coefficients. The endogenous variables are $y_{t}, \pi_{t},\left(e_{t}-p_{t}\right)$, and $\left(r_{t}-r_{t}^{*}\right)$, whereas $y_{t}^{*}, \pi_{t}^{*}$ and $p_{t}^{\text {oil }}$ are treated as weakly exogenous, non-cointegrated $I(1)$ variables. The test statistics refer to Johansen's log-likelihood-based maximum eigenvalue and trace statistics and are computed using 121 observations from 1979Q4 to 2009Q4.

relation be the output gap, given by equation (1) and normalised on $y_{t}$; and the second relation be the one between domestic and foreign inflations, defined by equation (3) and normalised on $\pi_{t}$. That is:

$$
\boldsymbol{\beta}_{E X}^{\prime}=\left(\begin{array}{ccccccc}
-1 & \beta_{12} & \beta_{13} & 0 & \beta_{15} & \beta_{16} & \beta_{17} \\
\beta_{21} & -1 & \beta_{23} & \beta_{24} & \beta_{25} & \beta_{26} & 0
\end{array}\right),
$$

where the rows of $\boldsymbol{\beta}_{E X}^{\prime}$ correspond to $\mathbf{z}_{t}=\left(y_{t}, \pi_{t}, e_{t}-p_{t}, r_{t}-r_{t}^{*}, y_{t}^{*}, \pi_{t}^{*}, p_{t}^{o i l}\right)^{\prime}$. Using this exactly identified specification, we test the co-trending restrictions, $\boldsymbol{\beta}^{\prime} \boldsymbol{\delta}=\boldsymbol{\gamma}=\left(\gamma_{y}, \gamma_{\pi}\right)^{\prime}=\mathbf{0}$. The log-likelihood ratio (LR) statistic for jointly testing the two co-trending restrictions is asymptotically distributed as a chi-squared variate with two degrees of freedom and takes the value 7.91. Therefore, based on the asymptotic distribution, the co-trending restrictions are rejected at the 5 percent but not the 1 percent level. However, given that the LR tests could over-reject in small samples such as ours (see, for example, Gredenhoff and Jacobson (2001) as well as Gonzalo (1994), Haug (1996) and Abadir et al. (1999)), we compute bootstrapped critical values based on 1,000 replications of the LR statistic. The bootstrapped critical values for the joint test of the two co-trending restrictions is 9.91 and 15.26 at the 5 and 1 percent levels respectively, as compared to the LR statistic of 7.91. Therefore, based on the bootstrapped critical values, the co-trending restrictions cannot be rejected at conventional levels of significance.

\subsubsection{Testing Long-Run Theory Restrictions}

To investigate the theory restrictions on the output equation, we impose the co-trending restrictions and maintain the exactly identified specification on the second long-run relation, while setting

$$
\beta_{12}=0, \beta_{16}=0 \text {, and } \beta_{13}=\beta_{17}=\alpha .
$$


That is, we impose the coefficients of the real exchange rate and oil prices to be the same, but allow for the coefficient on foreign output, $\beta_{16}$, to be freely estimated. Imposing these additional restrictions on the first cointegrating relation yields:

$$
\hat{\psi}_{1}=\underset{(0.0698)}{0.9846}, \hat{\psi}_{2}=\hat{\psi}_{3}=\hat{\alpha}=\underset{(0.0616)}{0.2050}
$$

where the figures in brackets are asymptotic standard errors. The LR statistic for testing the additional three restrictions is 26.50 which is to be compared to the bootstrapped critical values of 21.45 at the 5 percent level and 29.06 at the 1 percent level. Therefore, these restrictions are rejected at the 5 percent significance level, but not at the 1 percent level. The test outcome is inconclusive, but we continue imposing the above restrictions whilst considering the other theory restrictions, and return to them to see if they continue to be supported by the data once the other restrictions are imposed.

The implicit estimate of $\theta$ given by $0.9846 /(1-0.2050)=1.24$ is significantly larger than unity suggesting that foreign technology is diffused and adapted very successfully by the domestic economy in the long run. As a result, technological growth in Jordan is faster than in the rest of the world, which pushes Jordanian output growth above its trading partners. This can also be seen in Figure 5a, in which domestic output grows faster than foreign output during most periods, and especially since the 2002 oil price boom which resulted in larger external income flows to Jordan. Therefore, we do not impose that $\theta=1$ and allow $\psi_{1}=\beta_{16}$ to be freely estimated.

Turning to the second long-run equation, the theoretical restrictions in terms of the elements of $\boldsymbol{\beta}$ in equation (12) require four further restrictions, namely:

$$
\beta_{21}=0, \beta_{23}=0, \beta_{24}=0, \text { and } \beta_{25}=0 \text {. }
$$

Imposing these additional restrictions on $\boldsymbol{\beta}$ yields:

$$
\hat{\psi}_{1}=\underset{(0.0727)}{0.9902,} \quad \hat{\alpha}=\underset{(0.0717)}{0.2519,}, \hat{\phi}_{1}=\underset{(0.2774)}{0.7558}
$$

The coefficient on foreign inflation is close to unity and the null hypothesis that it is equal to 1 cannot be rejected. Imposing $\hat{\phi}_{1}=1$ and re-estimating subject to the 8 over-identifying restrictions (and the two co-trending ones) described above, we obtain:

$$
\hat{\psi}_{1}=\underset{(0.0753)}{1.0074}, \quad \hat{\alpha}=\underset{(0 . .0770)}{0.2477}, \quad \phi_{1}=1 .
$$

As before, the implicit estimate of $\theta=1.0074 /(1-0.2477)=1.34$ is significantly larger than 1, thus supporting the hypothesis that Jordanian output growth is faster than its foreign counterpart due to higher technological growth in Jordan. Given that the coefficient on foreign output is not significantly different from unity, the above relation suggests that the deviation of Jordanian real output from foreign output in the long run can be solely attributed to the price of oil. That is, an oil price boom, by increasing external income, helps capital accumulation and thus raises output. This result also suggests that if oil prices played no role in the Jordanian economy, domestic and foreign growth rates would move on a one-to-one basis, $y_{t}-y_{t}^{*}=\xi_{y, t}$, and as a result Jordanian growth would be on par with the rest of the world. 
The estimated share of capital in output, $\hat{\alpha}=0.2477$, although being lower than 0.38 and 0.5 as reported for Jordan between 1975-1994 in International Monetary Fund (1998), ${ }^{5}$ does lie in the range as estimated for a panel of 29 countries in Pedroni (2007). The LR statistic for testing the eight over-identifying restrictions on the long-run relations is 31.77 as compared to the bootstrapped critical values of 32.13 and 40.65 at the 5 and 1 percent significance levels, respectively. Thus, these restrictions cannot be rejected at the conventional levels of significance, and once the effects of oil prices are taken into account, the estimates support output growth convergence between Jordan and the rest of the world. ${ }^{6}$

\subsubsection{Using External Income as Opposed to Oil Prices}

As described in Section A, from a long-run perspective, given the cointegration results between $x_{t}$ and $p_{t}^{o i l}$, only one of the two variables needs to be included in the model. However, to check the robustness of our results, we re-estimate the model with external income, $x_{t}$, rather than the price of oil. $\mathbf{z}_{t}=\left(\mathbf{x}_{t}^{\prime}, \mathbf{x}_{t}^{* \prime}\right)^{\prime}$ in equation (11) is now partitioned into a $5 \times 1$ vector of endogenous variables, $\mathbf{x}_{t}=\left(y_{t}, \pi_{t}, e_{t}-p_{t}, r_{t}-r_{t}^{*}, x_{t}\right)$, and a $2 \times 1$ vector of the weakly exogenous variables, $\mathbf{x}_{t}^{*}=\left(y_{t}^{*}, \pi_{t}^{*}\right)^{\prime}$.

\section{Table 5: Cointegration Rank Test Statistics for the VARX*(2,2) Model}

\begin{tabular}{|c|c|c|c|c|}
\hline$H_{0}$ & $H_{1}$ & Test Statistic & 95\% Critical Values & 90\% Critical Values \\
\hline \multicolumn{5}{|c|}{ (a) Maximal eigenvalue statistic } \\
\hline$r=0$ & $r=1$ & 59.06 & 49.82 & 45.98 \\
\hline$r \leq 1$ & $r=2$ & 39.58 & 42.34 & 39.08 \\
\hline$r \leq 2$ & $r=3$ & 26.85 & 34.07 & 31.72 \\
\hline \multicolumn{5}{|c|}{ (b) Trace statistic } \\
\hline$r=0$ & $r=1$ & 154.06 & 123.02 & 118.54 \\
\hline$r \leq 1$ & $r=2$ & 95.00 & 89.59 & 84.63 \\
\hline$r \leq 2$ & $r=3$ & 55.42 & 60.44 & 57.08 \\
\hline$r \leq 3$ & $r=4$ & 28.57 & 38.52 & 35.33 \\
\hline
\end{tabular}

Notes: The underlying VARX* model is of order $(2,2)$ and contains unrestricted intercept and restricted trend coefficients. The endogenous variables are $y_{t}, \pi_{t},\left(e_{t}-p_{t}\right),\left(r_{t}-r_{t}^{*}\right)$, and $x_{t}$ whereas $y_{t}^{*}$ and $\pi_{t}^{*}$ are treated as weakly exogenous, non-cointegrated $I(1)$ variables. The test statistics refer to Johansen's loglikelihood-based maximum eigenvalue and trace statistics and are computed using 121 observations from 1979Q4 to 2009Q4.

Table 5 reports the cointegration rank test statistics for the VARX* $(2,2)$ model. The trace statistic suggest the presence of two long-run relations at the 5 percent level, while

\footnotetext{
${ }^{5}$ As International Monetary Fund (1998) did not have data for gross fixed capital formation, the implicit GDP deflator was used to derive a proxy for this. This might explain the large estimates for $\alpha$.

${ }^{6}$ We also included a dummy as a deterministic variable in our model to capture the Jordanian balance of payments crisis during late-1988 and early-1989, as well as the 1990/1991 regional crisis due to the Persian Gulf War. However, once the effects of external income (through changes in oil prices) are taken into account, the estimates of the model with the dummy variable suggest only a modest average decline in real output due to balance of payments crisis and the war. These results are not reported but are available upon request. Therefore we will concentrate on the model without the dummy variable.
} 
the maximal eigenvalue statistic indicates two cointegrating relationships at the 10 percent level, thus we set $r=2$.

As before, we take the first cointegrating relation to be the output equation and the second one the relationship between domestic and foreign inflations. Thus, the two exactly identified cointegrating vectors are now given by:

$$
\boldsymbol{\beta}_{E X}^{\prime}=\left(\begin{array}{ccccccc}
-1 & \beta_{12} & \beta_{13} & 0 & \beta_{15} & \beta_{16} & \beta_{17} \\
\beta_{21} & -1 & \beta_{23} & \beta_{24} & \beta_{25} & 0 & \beta_{27}
\end{array}\right),
$$

where the rows of $\boldsymbol{\beta}_{E X}^{\prime}$ correspond to $\mathbf{z}_{t}=\left(y_{t}, \pi_{t}, e_{t}-p_{t}, r_{t}-r_{t}^{*}, x_{t}, y_{t}^{*}, \pi_{t}^{*}\right)^{\prime}$. Note that the variables have different orders in $\mathbf{z}_{t}$ due to the exclusion of $p_{t}^{\text {oil }}$ and the inclusion of $x_{t}$. We impose the two co-trending restrictions as well as the seven over-identifying restrictions as before:

$$
\begin{aligned}
& \boldsymbol{\beta}^{\prime} \boldsymbol{\delta}=\boldsymbol{\gamma}=\mathbf{0}, \\
& \beta_{12}=0, \beta_{17}=0, \text { and } \beta_{13}=\beta_{15}=\alpha, \\
& \beta_{21}=0, \beta_{23}=0, \beta_{24}=0, \text { and } \beta_{25}=0 .
\end{aligned}
$$

and re-estimate equation (11) to obtain:

$$
\hat{\psi}_{1}=\underset{(0.0692)}{0.7122,}, \hat{\alpha}=\underset{(0.0640)}{0.3744,}, \hat{\phi}_{1}=\underset{(0.2494)}{0.9325}
$$

The LR statistics for testing these restrictions is 22.65 as compared with the bootstrapped critical values of 23.89 at the 10 percent significance level and 26.16 at the 5 percent level. Thus, these restrictions cannot be rejected even at the 10 percent level. Notice that the coefficient of foreign inflation in the second cointegrating vector is close to unity and so is the implicit estimate of $\theta=0.7122 /(1-0.3744)=1.14$. Imposing $\phi_{1}=1$ and $\beta_{15}+\beta_{14}=$ $1 \Longrightarrow \theta=1$, yields:

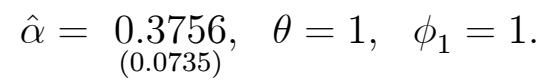

There are now nine over-identifying restrictions on the long-run relations, and the LR statistic for testing these restrictions is 25.94 as compared to the bootstrapped critical values of 27.17 and 30.12 at the 10 and 5 percent significance levels, respectively. Clearly, the restrictions are not rejected even at the 10 percent significance level.

The impact of external income on GDP $(\widehat{\alpha}=0.3756)$ is larger than the estimate obtained for the model with $p_{t}^{\text {oil }}(\widehat{\alpha}=0.2477)$. This is expected as $p_{t}^{\text {oil }}$ measures the net effect of an increase in oil prices on income: the positive effect is due to larger inflows of external income which in turn increases GDP as measured above, while the negative effect is due to the increase in the cost of importing oil. Clearly, given the results in Section 5.3.1, the positive impact dominates the negative effect.

\section{Short-Run Dynamics}

We use the estimated model with the price of oil to examine the dynamic responses of the Jordanian economy to various types of shocks. We are primary interested in the effects of an 
oil price shock, and so make use of the Generalized Impulse Response Functions (GIRFs), developed in Koop et al. (1996) and Pesaran and Shin (1998). We also compare the effects of an oil price shock for Jordan with those of large oil exporters such as Iran and Saudi Arabia, as our theory suggests that the role of oil in the long run should be similar. Furthermore, we look at the effects of the shocks to foreign output and inflation. Note that the GIRFs are invariant to the ordering of the variables in the VARX* model, while the orthogonalized impulse responses popularized in macroeconomics by Sims (1980) are not.

We also investigate the error-correcting property of the model and the estimates of the reduced form error correction equations. But first, we consider the effects of a system wide shock on the two cointegrating relations using persistence profiles (PPs), as developed in Lee and Pesaran (1993) and Pesaran and Shin (1996). While on impact the PPs are normalized to take the value of unity, they must eventually tend to zero if the long-run relationship under consideration is cointegrating. The rate at which they tend to zero then provides information on the speed with which equilibrium correction takes place in response to system wide shocks.

\subsection{Persistence Profiles}

To investigate the speed of convergence to equilibrium for the cointegrating relations in the Jordanian model, we turn to Figure 6, which depicts the effects of a system-wide shock to the two cointegrating relations with 95 percent bootstrapped confidence bounds. As can be seen, the speed of convergence to equilibrium for the inflation equation is very fast; the half life of the shock is less than a quarter while the life of the shock is around 14 quarters. This can be attributed to the relative openness of the economy and the high pass-through of international prices to domestic markets.

For the output equation, on the other hand, the speed of convergence is slower. The half life of the shock is 7 quarters with the life of the shock being around 20 quarters. This is in line with what is reported for Saudi Arabia, Switzerland and the United Kingdom, but the speed is slower than that in the Iranian model; see Assenmacher-Wesche and Pesaran (2009), Esfahani et al. (2009), and Garratt et al. (2006). Note also that the persistence profile initially exceeds unity, i.e. over-shoots, but tends to zero in the long run, verifying that the long-run output equation, defined in equation (1), is indeed cointegrating.

Figure 6: The Persistence Profiles of the Effect of a System-wide Shock to the Cointegrating Relations (with 95 Percent Bootstrapped Confidence Bounds)
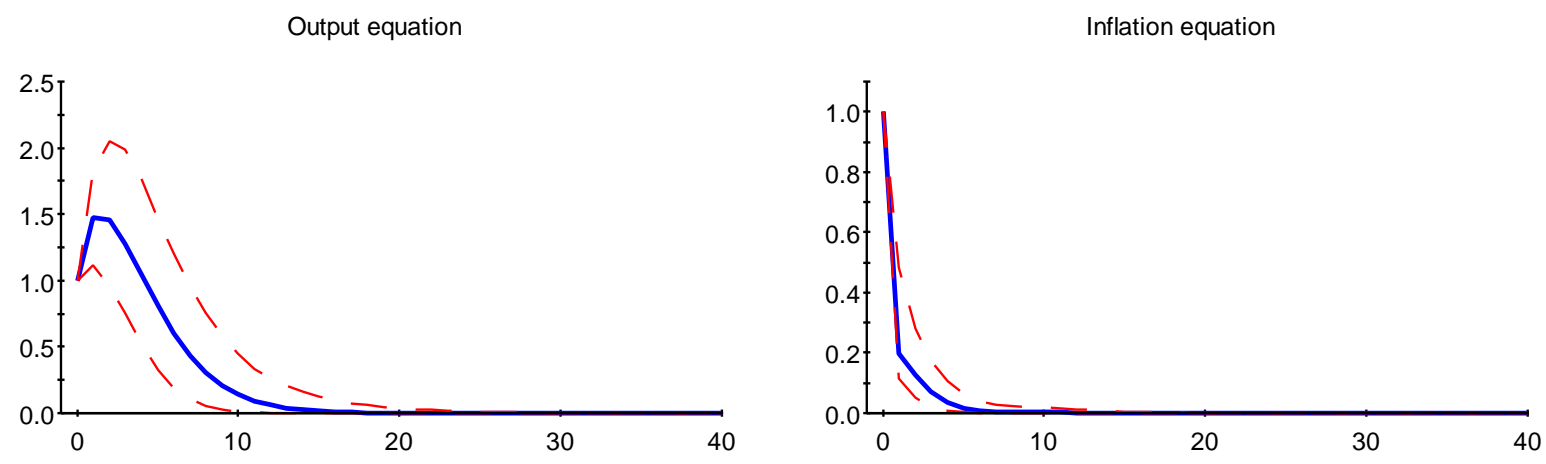


\subsection{Generalized Impulse Responses (GIRFs)}

We compute the GIRFs for shocks to the exogenous variables in our model: $y_{t}^{*}, \pi_{t}^{*}$, and $p_{t}^{\text {oil }}$. Although GIRFs can also be computed for the four endogenous variables, their interpretation are less straightforward and so these are not discussed here. Figure 7 shows the GIRFs of a unit shock, equal to one standard error, ${ }^{7}$ to the price of oil. As can be seen, a positive oil price shock increases domestic output, $y_{t}$, strengthens the real exchange rate, $e_{t}-p_{t}$, and increases domestic inflation, $\pi_{t}$, but has no statistically significant effect on the interest rate spread, $r_{t}-r_{t}^{*}$. As expected, the effects of the shock tends to be permanent, due to the presence of unit roots in the underlying variables (see Table 2). Quantitatively, the oil price shock increases domestic output by 4 percent and pushes inflation up by 0.5 percent per annum. It also leads to an exchange rate appreciation of around 4 percent. This seems to support the view that remittance inflows can generate Dutch disease in labor-exporting countries such as Jordan; see Fayad (2011) for more details. However, while our results show that following a positive oil shock, the exchange rate appreciates, the level of output also increases which does not fit well with the view that Dutch disease is a "curse" on economic activity.

Figure 7: Generalized Impulse Responses of a Positive Unit Shock to the Price of Oil (with 95 Percent Bootstrapped Confidence Bounds)
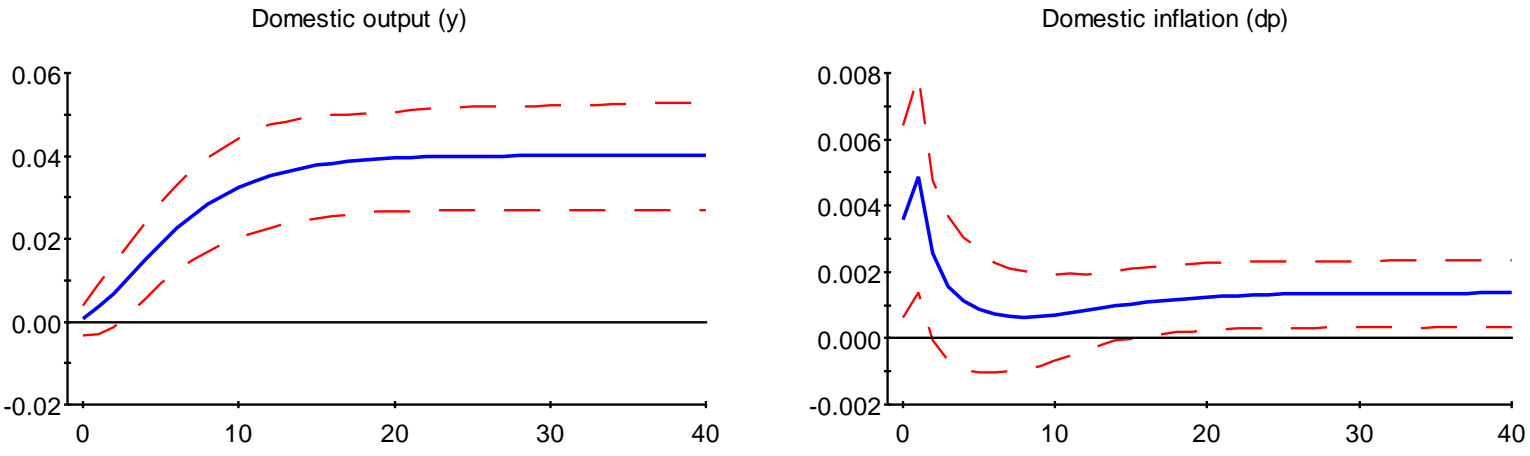

Real exchange rate (e-p)

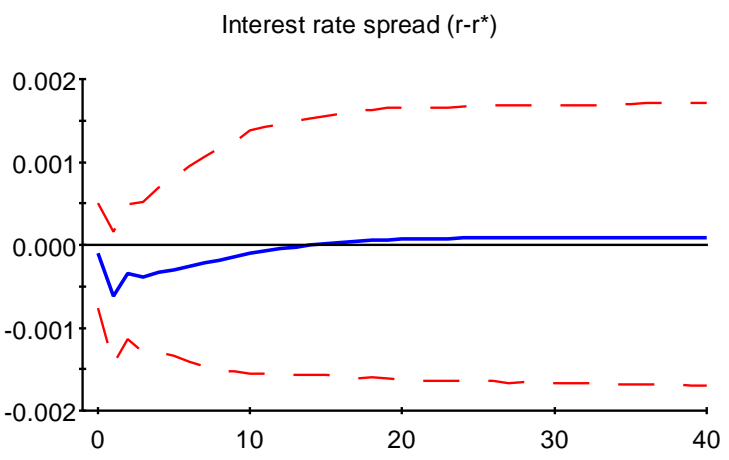

Interestingly, the effects of the oil price shock for Jordan are very similar to those reported

\footnotetext{
${ }^{7} \mathrm{~A}$ one standard error shock to the price of oil, foreign output and inflation is equivalent to $15,0.6$, and 0.4 percent respectively.
} 
Figure 8: Generalized Impulse Responses of a Positive Unit Shock to Foreign Output (with 95 Percent Bootstrapped Confidence Bounds)
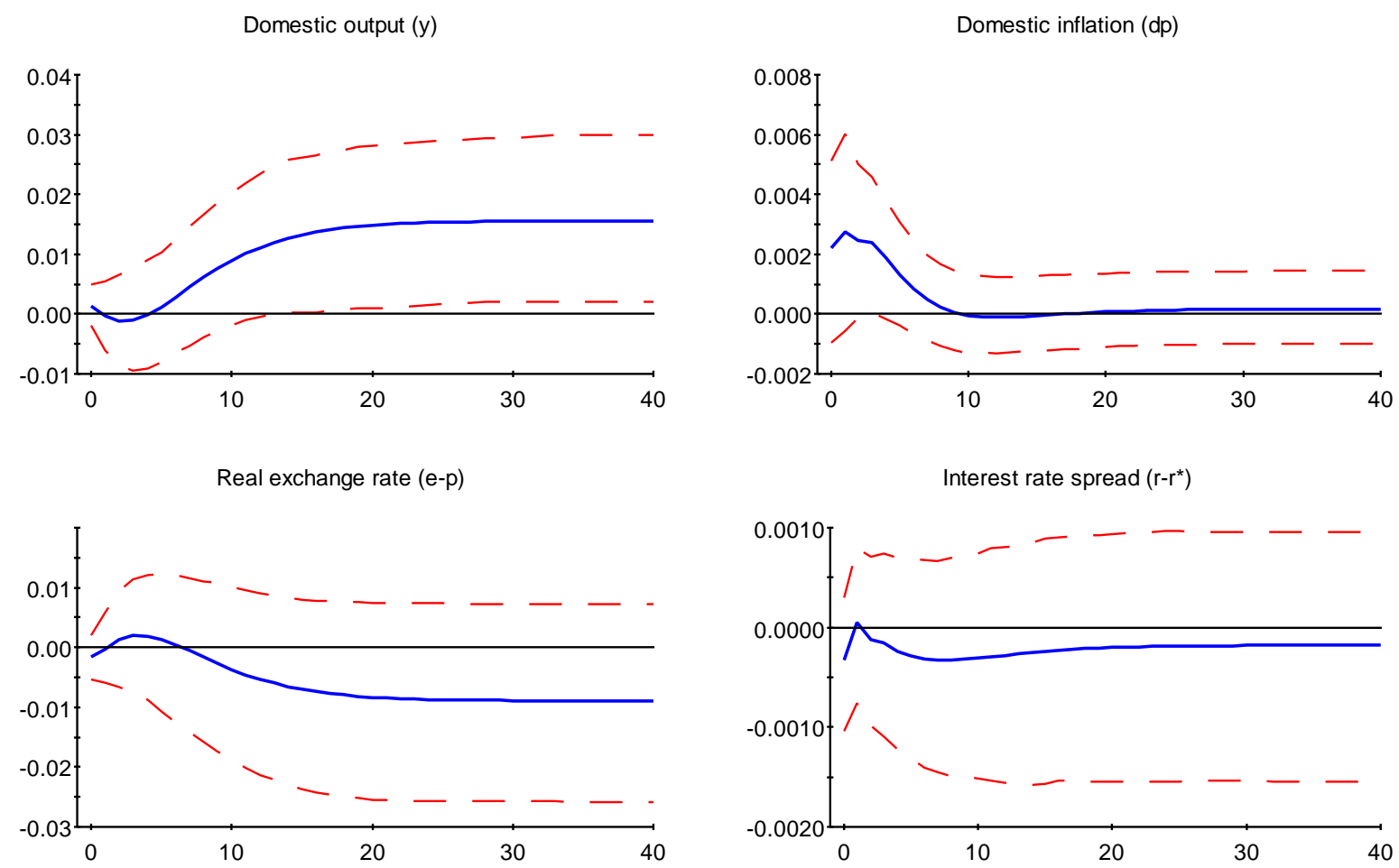

Figure 9: Generalized Impulse Responses of a Positive Unit Shock to Foreign Inflation (with 95 Percent Bootstrapped Confidence Bounds)
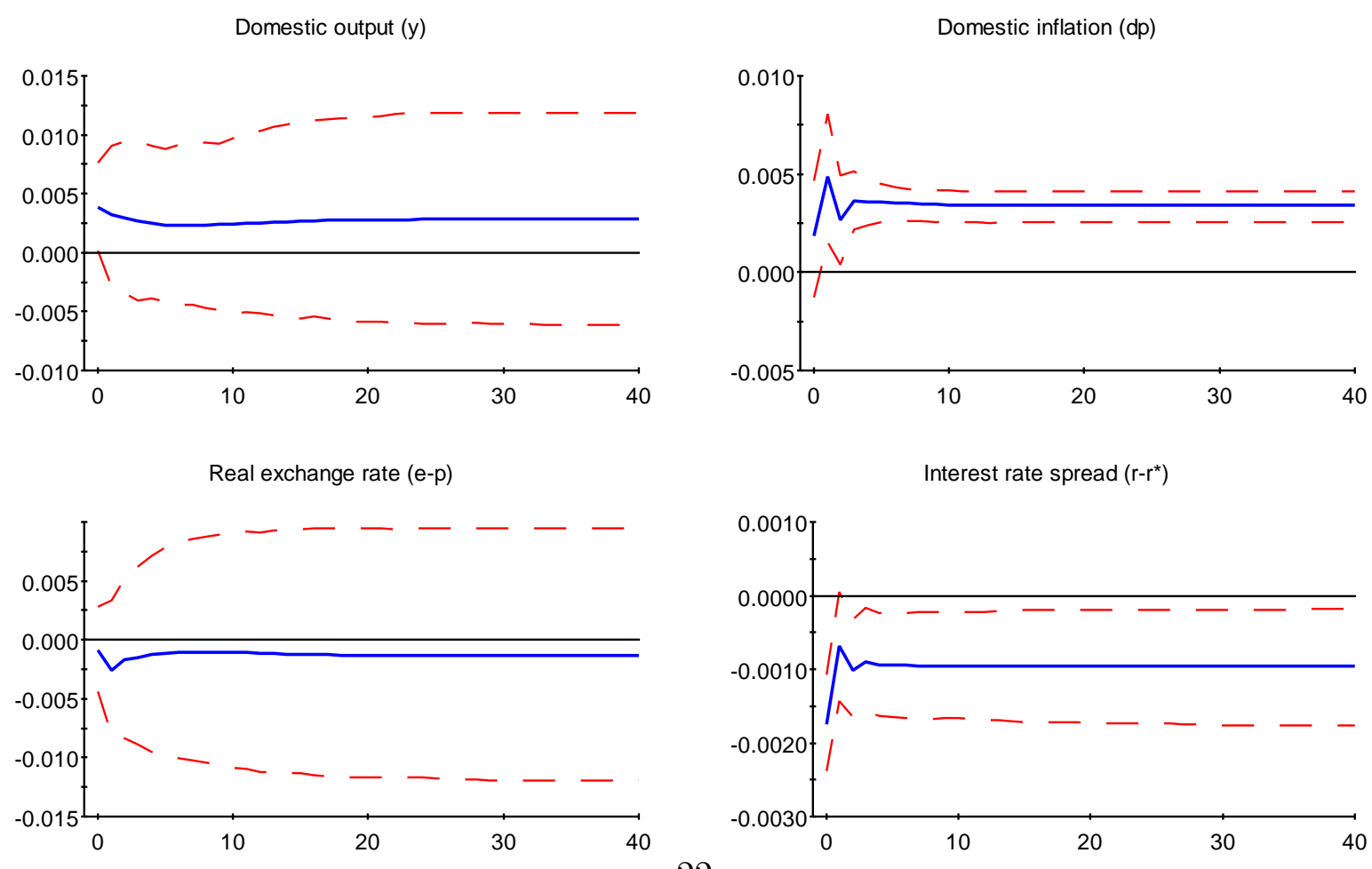
for Iran and Saudi Arabia in Esfahani et al. (2009). Although Iran and Saudi Arabia are major oil exporters while Jordan is an oil importer, we expect the price of oil to play a significant positive role in all of these economies - see the theory derived output equation (1) which holds for the three countries. While the channel of impact on these economies is through capital accumulation, the positive impact of oil price booms on the Iranian and Saudi Arabian economies are due to an increase in oil export revenues, while for the Jordanian economy it is due to higher inflows of external income.

Figures 8 and 9 show the GIRFs of a unit shock to foreign output and inflation. While the foreign output shock significantly increases domestic output by around 1.6 percent in the long run, its effect on the remaining variables is statistically insignificant. On the other hand, following a positive shock to foreign inflation, domestic inflation increases by 1.4 percent per annum while the interest rate spread decreases by 0.4 percent per annum. Therefore, while foreign output and inflation shocks have some effect on the endogenous variables in our model, their effects are relatively muted as compared to the oil price shock. Nevertheless, this illustrates the importance of including foreign variables in any macro model for Jordan.

\subsection{Error-Correction Equations}

The error-correcting property of the model can also be seen in the size and significance of the coefficients of the error correcting terms, $\boldsymbol{\xi}_{t}=\left(\xi_{t, y}, \xi_{t, \pi}\right)^{\prime}$, defined by equation (7). The estimates of the reduced form error correction equations are given in Table 6, from which we

can see that $\hat{\xi}_{t-1, y}$ is statistically significant in the output, inflation, and the real exchange rate equations, but not the interest rate spread equation. On the other hand, $\hat{\xi}_{t-1, \pi}$ is significant in both the inflation and interest rate spread equations but not in the remaining two equations. Thus, the long-run relations make an important contribution in most of the core equations.

Turning to the actual and fitted values for each of the four core equations in Figure 10, and their associated residuals, we observe that the fitted values seem to track the main movements of the dependent variables reasonably well. This is the case even though there are some large outliers, especially for the interest rate spread equation, $d\left(r-r^{*}\right)$, in the late 1980 s and the beginning of the 1990s and for the real exchange rate, $d(e-p)$, and inflation, $d(d p)$, equations in the beginning of the sample as well as mid 1990s. The presence of large outliers are reflected in the massive rejection of the normality of the errors in the case of interest rate spread equation (see Table 6). Finally, we observe that the explanatory power of all the equations seem reasonable, with $\bar{R}^{2}$ lying in the range [0.260, 0.523$]$, further illustrating that the core model fits the historical data well in the sense of capturing the movements of the main macroeconomic variables in Jordan over the period 1979 to 2009. 
Table 6: Reduced-form Error Correction Equations of the VECX*

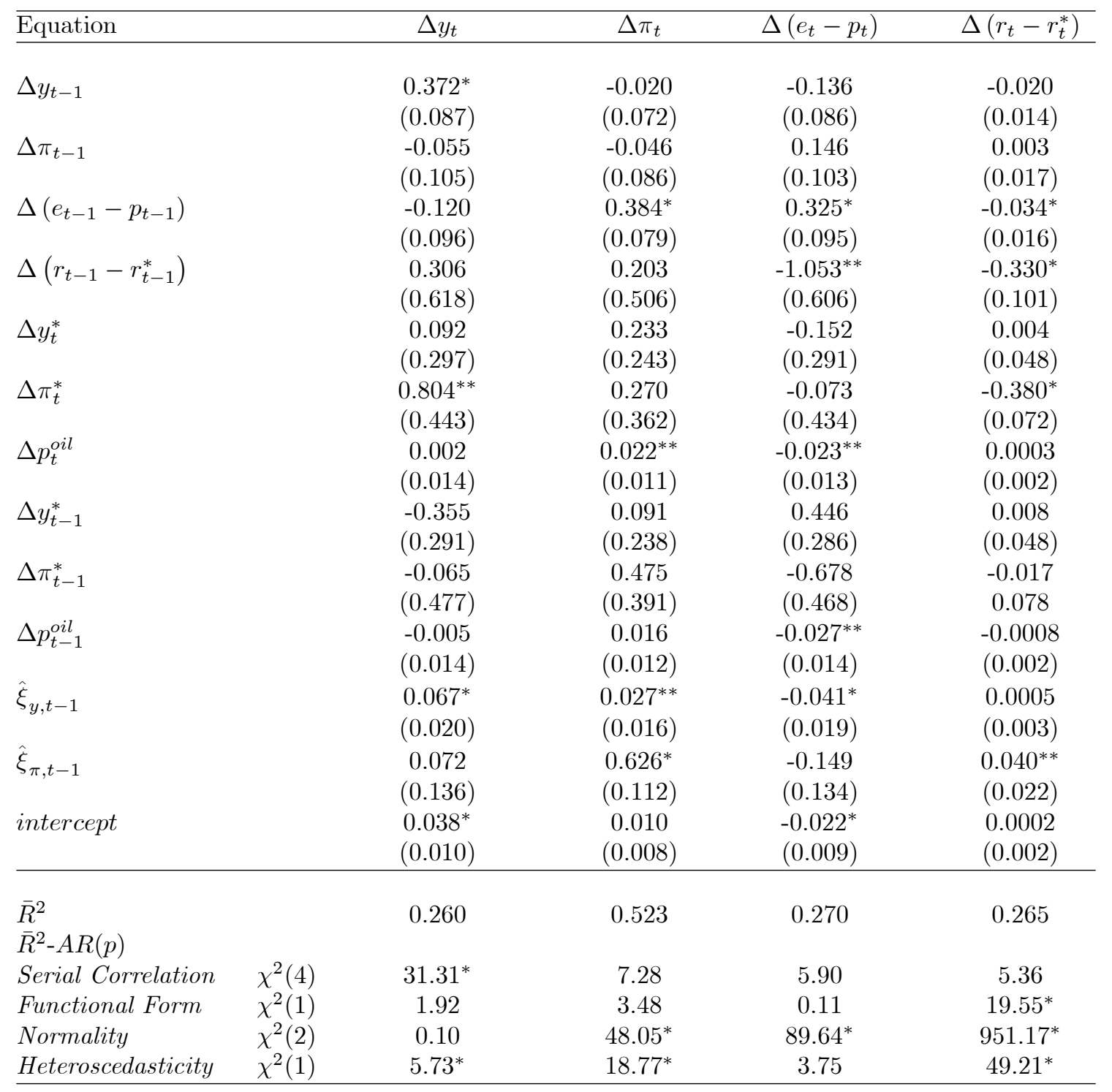

Notes: *denotes significance at the 5 percent level and ${ }^{* *}$ denotes significance at the 10 percent level. Critical values are 3.84 for $\chi^{2}(1), 5.99$ for $\chi^{2}(2)$ and 9.49 for $\chi^{2}(4) . \bar{R}^{2}$ is the adjusted squared multiple correlation coefficient, and $\bar{R}^{2}-\mathrm{AR}(\mathrm{p})$ refers to the $\bar{R}^{2}$ of a univariate autoregressive equation. The sample period is 1979Q4 to 2009Q4. The two error correction terms are given by:

$$
\begin{aligned}
& \xi_{y, t}=y_{t}-\underset{(0.0770)}{0.2477}\left(e_{t}-p_{t}\right)-\underset{(0.0753)}{1.0074 y_{t}^{*}}-\underset{(0.0770)}{0.2477} p_{t}^{\text {oil }}, \\
& \xi_{\pi, t}=\pi_{t}-\pi_{t}^{*}
\end{aligned}
$$


Figure 10: Actual, Fitted, and Residuals for the Core Equations

(a) Output equation

Actual and fitted

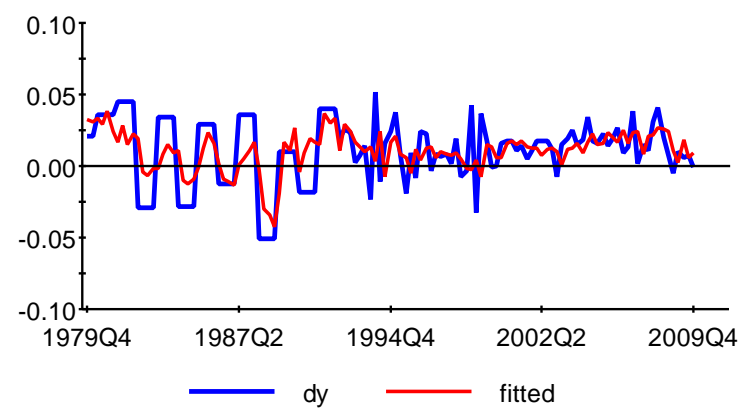

(b) Inflation equation

Actual and fitted

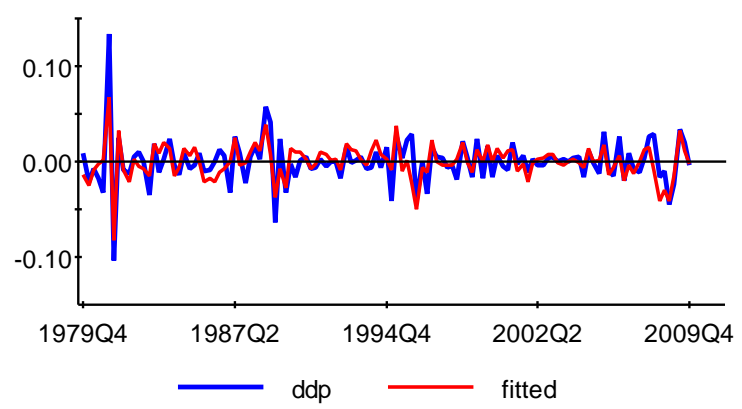

(c) Real exchange rate equation

Actual and fitted

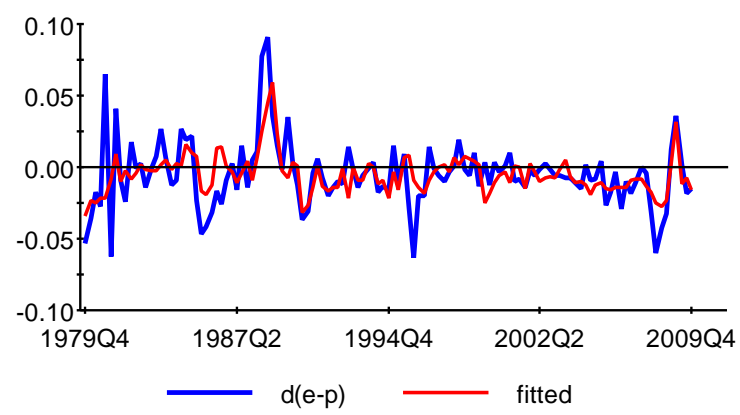

(d) Interest rate spread equation

Actual and fitted

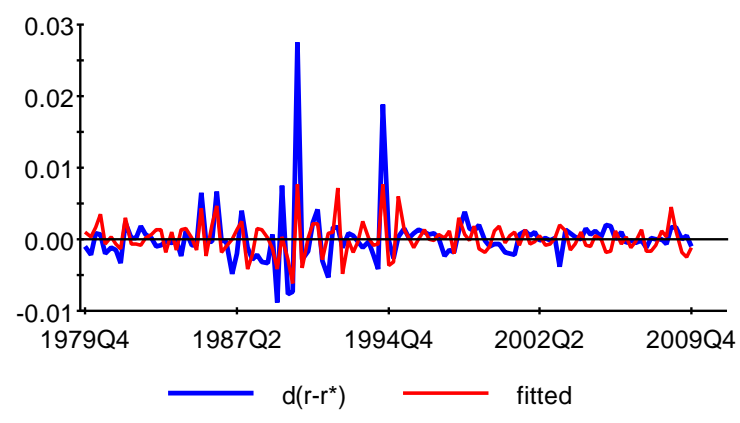

Residuals

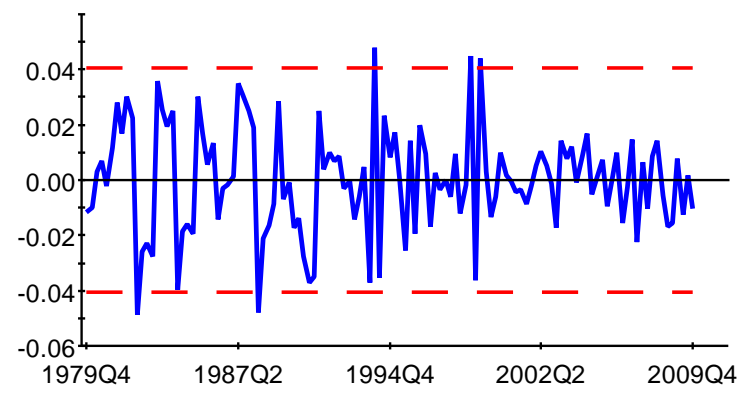

Residuals

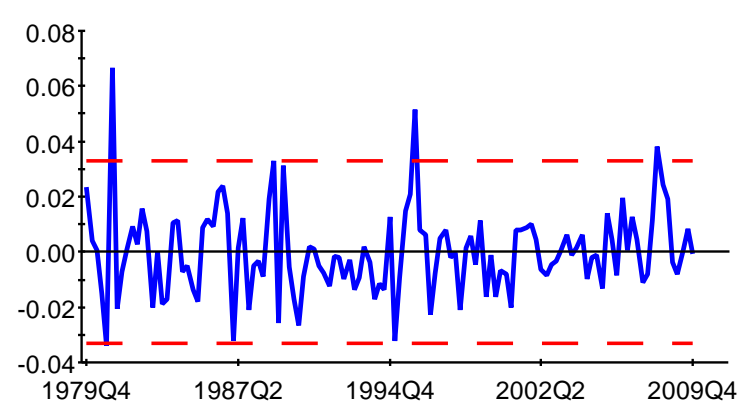

Residuals

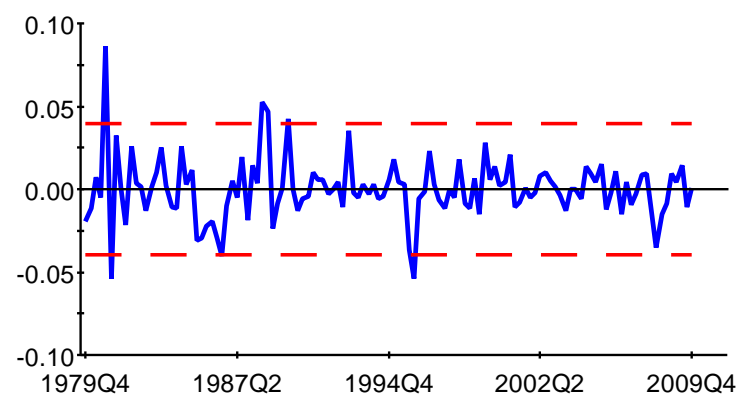

Residuals

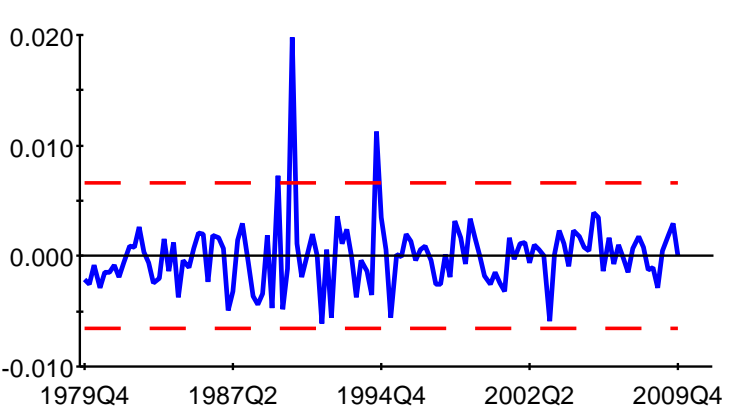




\section{Concluding Remarks}

We provided a cointegrating VARX* analysis of the Jordanian economy in a global context. The specified model combines the implications of economic theory for identification of the long-run relationships and a data-driven approach to modeling the short-run dynamics. We identified two cointegrating relations amongst the variables considered: (i) a relationship between domestic and foreign inflations; and (ii) an augmented output equation, which is a systematic long-term interaction between real external income (or price of oil), domestic output and foreign GDP. The likelihood ratio tests did not reject the over-identifying restrictions suggested by economic theory. This provides evidence that the price of oil, through its impact on external income and in turn on capital accumulation, is one of the main long-run drivers of real output in Jordan. Moreover, the well-behaved persistence profiles of the longrun relations supported the validity of these restrictions. Using generalized impulse response functions (GIRFs), we also analyzed the short-term implications of external shocks on the core macroeconomic variables of Jordan, and in doing so, illustrated the importance of oil price shocks in particular, but also foreign output and inflation shocks, to the Jordanian economy.

Jordan's economy is subject to frequent and large external income shocks and the tradables sector is relatively small. Given that any sudden stops or reversal of capital/current inflows could expose Jordan to significant risks, macroeconomic and structural policies should be conducted in a way that the vulnerability of the Jordanian economy to these disturbances is reduced. To this end, an outward-oriented growth strategy based on a more balanced contribution of the tradables and nontradables sectors could prove helpful for two reasons. First, it would allow the Jordanian export sector to diversify and it would provide for external stimuli through exports rather than through net current/capital transfers from the region. Second, increased trade in goods and services would also allow for the transfer of technology and knowledge to Jordan, thereby raising productivity. Nevertheless, the expected acceleration in the development of the tradables sector could be slow to materialize. As the regional economic and political environment remains subject to uncertainties and as intra-regional trade continues to be hampered by high trade barriers, higher tradables sector growth in the future is likely to require the search for new markets outside the region.

The research in this paper can be extended in several directions. Firstly, by linking the Jordanian VARX* model to the global VAR (GVAR) model recently developed in Dees et al. (2007), we could investigate the different regional shocks, as well as differential effects of supply and demand shocks, on the Jordanian economy. Secondly, it would also be of interest to investigate the extent to which the long-run effects of oil prices and external income on real output outlined in this paper can be found in the case of other labour exporting countries that receive large inflow of remittances from major oil economies, such as Bangladesh and the Dominican Republic. 


\section{References}

Abadir, K., K. Hadri, and E. Tzavalis (1999). The Influence of VAR Dimensions on Estimator Biases. Econometrica 6\%, 163-181.

Assenmacher-Wesche, K. and M. H. Pesaran (2009). A VECX* Model of the Swiss Economy. Swiss National Bank Economic Studies No. 6.

Beidas-Strom, S. and T. Poghosyan (2011). An Estimated Dynamic Stochastic General Equilibrium Model of the Jordanian Economy. IMF Working Paper No. 11/28.

British Petroleum, . (2010). Statistical Review of World Energy. Beacon Press.

Dees, S., F. di Mauro, M. H. Pesaran, and L. V. Smith (2007). Exploring the International Linkages of the Euro Area: A Global VAR Analysis. Journal of Applied Econometrics 22, $1-38$.

Elliott, G., T. J. Rothenberg, and J. H. Stock (1996). Efficient Tests for an Autoregressive Unit Root. Econometrica 64, 813-836.

Esfahani, H. S., K. Mohaddes, and M. H. Pesaran (2009). Oil Exports and the Iranian Economy. Cambridge Working Papers in Economics 0944.

Fayad, G. (2011). Remittances: Dutch disease or export-led growth. OxCarre Research Paper $5 \%$.

Garratt, A., K. Lee, M. H. Pesaran, and Y. Shin (2003). A Long Run Structural Macroeconometric Model of the UK. The Economic Journal 113, 412-455.

Garratt, T., K. Lee, M. H. Pesaran, and Y. Shin (2006). Global and National Macroeconometric Modelling: A Long Run Structural Approach. Oxford University Press, Oxford.

Gonzalo, J. (1994). Five Alternative Methods of Estimating Long-run Equilibrium Relationships. Journal of Econometrics 60(1-2), 203 - 233.

Gredenhoff, M. and T. Jacobson (2001). Bootstrap Testing Linear Restrictions on Cointegrating Vectors. Journal of Business and Economic Statistics 19, 63-72.

Haug, A. (1996). Tests for Cointegration A Monte Carlo Comparison. Journal of Econometrics 71, 89-115.

International Monetary Fund, . (1998, April). Jordan: Selected Issues. SM/98/84.

International Monetary Fund, . (2010a). Balance of Payments Statistics.

International Monetary Fund, . (2010b). Direction of Trade Statistics.

International Monetary Fund, . (2010c). Jordan - 2010 Article IV Consultation - Staff Report and Public Information Notice. Country Report No. 10/29\%.

International Monetary Fund, . (2010d). INS. 
International Monetary Fund, . (2010e). International Financial Statistics.

Koop, G., M. H. Pesaran, and S. M. Potter (1996). Impulse Response Analysis in Nonlinear Multivariate Models. Journal of Econometrics 74, 119-147.

Lee, K. and M. H. Pesaran (1993). Persistence Profiles and Business Cycle Fluctuations in a Disaggregated Model of UK Output Growth. Ricerche Economiche 47, 293-322.

Maziad, S. (2009). Monetary Policy and the Central Bank in Jordan. IMF Working Paper No. 09/191.

OPEC, . (2009). OPEC Annual Statistical Bulletin. Ueberreuter Print und Digimedia.

Park, H. and W. Fuller (1995). Alternative Estimators and Unit Root Tests for the Autoregressive Process. Journal of Time Series Analysis 16, 415-429.

Pedroni, P. (2007). Social Capital, Barriers to Production and Capital Shares: Implications for the Importance of Parameter Heterogeneity from a Nonstationary Panel Approach. Journal of Applied Econometrics 20, 429-451.

Pesaran, M. and B. Pesaran (2009). Microfit 5.0: An Interactive Econometric Software Package. Oxford University Press, Oxford.

Pesaran, M. H. (2004). General Diagnostic Tests for Cross Section Dependence in Panels. CESifo Working Paper 1229.

Pesaran, M. H. and Y. Shin (1996). Cointegration and Speed of Convergence to Equilibrium. Journal of Econometrics 11, 117-143.

Pesaran, M. H. and Y. Shin (1998). Generalised Impulse Response Analysis in Linear Multivariate Models. Economics Letters 58, 17-29.

Pesaran, M. H., Y. Shin, and R. J. Smith (2000). Structural Analysis of Vector Error Correction Models with Exogenous I(1) Variables. Journal of Econometrics 97, 293-343.

Pesaran, M. H. and R. Smith (2006). Macroeconomic Modelling With A Global Perspective. The Manchester School Supplement, 24-49.

Sims, C. (1980). Macroeconomics and Reality. Econometrica 48, 1-48.

Smith, L. and A. Galesi (2010). GVAR Toolbox 1.0. 